\title{
Recent advances on organic blue thermally activated delayed fluorescence (TADF) emitters for organic light-emitting diodes (OLEDs)
}

\author{
Thanh-Tuân Bui ${ }^{1}$, Fabrice Goubard ${ }^{1}$, Malika Ibrahim-Ouali ${ }^{2}$, Didier Gigmes ${ }^{3}$ \\ and Frédéric Dumur ${ }^{*}$
}

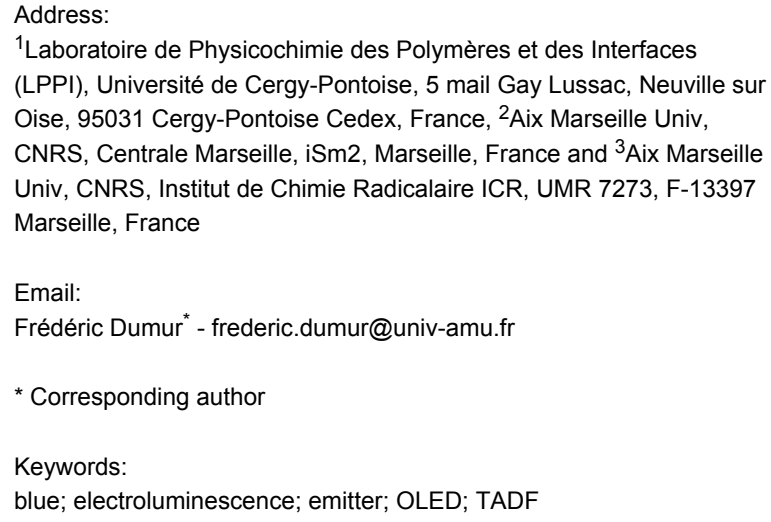

Beilstein J. Org. Chem. 2018, 14, 282-308. doi:10.3762/bjoc. 14.18

Received: 13 November 2017

Accepted: 19 January 2018

Published: 30 January 2018

This article is part of the Thematic Series "Recent advances in materials for organic light emitting diodes".

Guest Editor: E. Zysman-Colman

(c) 2018 Bui et al.; licensee Beilstein-Institut. License and terms: see end of document.

\begin{abstract}
The design of highly emissive and stable blue emitters for organic light emitting diodes (OLEDs) is still a challenge, justifying the intense research activity of the scientific community in this field. Recently, a great deal of interest has been devoted to the elaboration of emitters exhibiting a thermally activated delayed fluorescence (TADF). By a specific molecular design consisting into a minimal overlap between the highest occupied molecular orbital (HOMO) and the lowest unoccupied molecular orbital (LUMO) due to a spatial separation of the electron-donating and the electron-releasing parts, luminescent materials exhibiting small $S_{1}-T_{1}$ energy splitting could be obtained, enabling to thermally upconvert the electrons from the triplet to the singlet excited states by reverse intersystem crossing (RISC). By harvesting both singlet and triplet excitons for light emission, OLEDs competing and sometimes overcoming the performance of phosphorescence-based OLEDs could be fabricated, justifying the interest for this new family of materials massively popularized by Chihaya Adachi since 2012. In this review, we proposed to focus on the recent advances in the molecular design of blue TADF emitters for OLEDs during the last few years.
\end{abstract}

\section{Introduction}

Since the pioneering works of Tang and VanSlyke in 1987 [1], organic light emitting diodes (OLEDs) have known major evolutions of their structures, not only of the device stacking

but also of the materials composing the different layers [2]. The interest of both the scientific and industrial communities for organic electroluminescent devices is supported by the fact that 
OLEDs have been identified as the key-elements for the fabrication of the next generation display and lighting technology [3]. Notably, lightweight and thin devices can be fabricated onto flexible substrates, favouring the penetration of OLEDs in these two markets. With the aim at reducing the global energy demand on Earth, two parameters govern the power consumption of OLEDs, namely the quantum yield of luminescence of the light emitting material and the device stacking. Indeed, the driving voltage of OLEDs is highly sensitive to the thickness of the different layers, the charge transport ability of the materials but also to their energy levels. By minimizing the energy gaps between adjacent layers and facilitating charge injection from the electrodes, the injection and transportation of holes and electrons can be realized at lower operating voltages. The second parameter concerns the light-emitting ability of the emitter, which is directly related to the nature, and the photoluminescence quantum yield (PLQY) of the emitter. Based on spin statistics, upon electrical excitation, singlet and triplet excitons are formed in a 1:3 ratio [4]. In the case of fluorescent materials, only singlet excitons can be utilized for light emission, limiting the internal quantum efficiency (IQE) of fluorescent OLEDs to $25 \%$. Conversely, phosphorescent materials can both harvest singlet and triplet excitons for emission by intersystem crossing (ISC), enabling to reach a theoretical IQE of $100 \%$ for phosphorescent OLEDs [5]. As drawback, triplet emitters are transition-metal complexes mostly based on iridium, platinum and osmium and the scarcity of these metals on Earth, their toxicity and high cost make these materials unsuitable candidates for a mass-production of OLEDs [6]. However, efforts have also been carried out to incorporate emitters comprising less toxic metals, providing mitigate results when tested in devices $[7,8]$. In 2012, a breakthrough has been obtained by the Adachi group who developed purely organic materials capable to harvest both singlet and triplet excitons for emission [9]. This new family of light emitting materials capable to compete with the well-established triplet emitters and displaying a similar efficiency in devices by developing a new emission mechanism was immediately termed as the third generation of OLEDs emitters that consists of thermally activated delayed fluorescence (TADF) emitters. As specificity, these materials can thermally repopulate the singlet state from the triplet state by reverse intersystem crossing (RISC), leading to an increase of the luminescence intensity. From the OLEDs viewpoint, TADF emitters behave by harvesting both singlet and triplet excitons for radiative transition, excepted that the emission occurs from the singlet state and not from the triplet state (as observed for metal complexes) and that the triplet-triplet annihilation commonly observed with phosphorescent OLEDs [10] can be drastically reduced (see Figure 1). TADF materials can also be metal-free, addressing the fabrication cost and environmental issues. Therefore, TADF emitters retain the high efficiency of the second generation of emitters (triplet emitters), the stability of the first generation of fluorescent materials while eliminating the different problems observed with the two previous generations: triplet-triplet annihilation and low device stability for phosphorescent OLEDs, low IQE for fluorescent OLEDs.

To get full-color displays or white-light OLEDs, the combination of the three primary colors red green blue (RGB) is indispensable. At present, highly emissive and stable blue emitters are actively researched [11-16]. Several points justify the low availability of highly efficient blue materials. First, due to their large bandgaps $(\Delta E>3 \mathrm{eV})$, charge injection from the adjacent

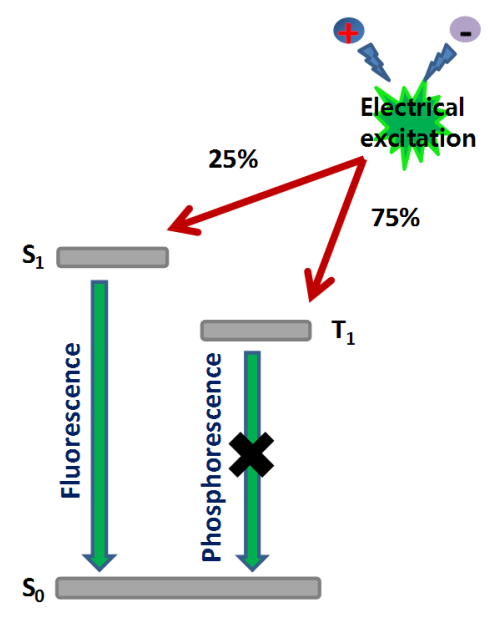

Fluorescent materials

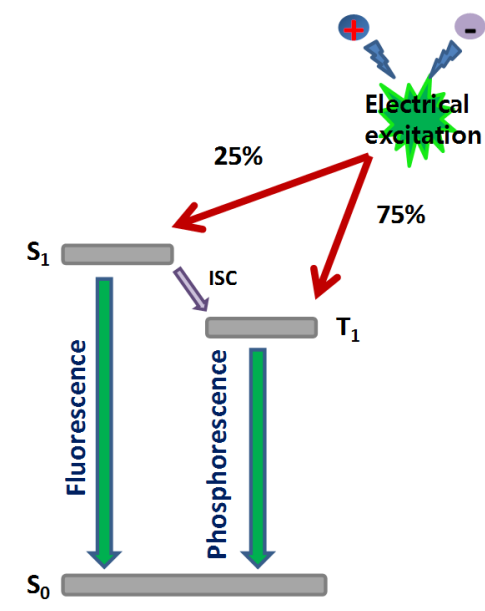

Phosphorescent materials

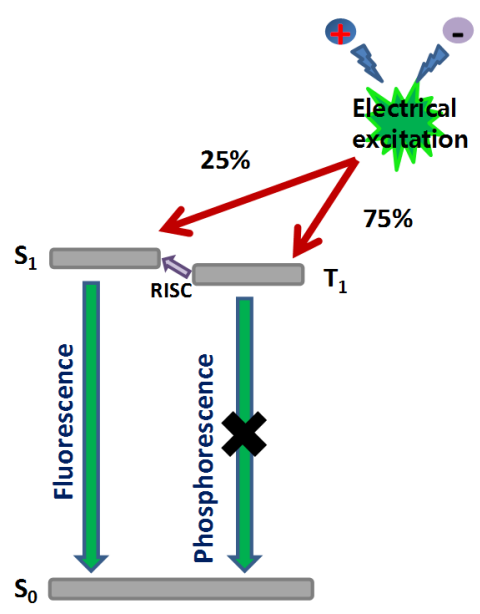

TADF materials 
layers is often difficult, requiring devices to be operated at high voltages [17]. Second, and still related to their wide bandgaps, the probability to transfer an electron from the ground to the excited stable state is considerably reduced, providing materials displaying PLQY greatly reduced compared to that observed for the other colors $[18,19]$. To end, the propensity of blue emitters to rapidly degradate upon device operation is well established, resulting in a fast and irreversible color shift $[20,21]$. In this context, TADF blue emitters have been identified as promising candidates to address the color purity, quantum efficiency and long-term device stability issues. Due to the enthusiasm of the scientific community for TADF emitters, this research field evolves extremely rapidly. In this review, a summary of the strategies developed during the last years to design organic blue TADF emitters is presented. It has to be noticed that the values of EQEs reported in the different tables correspond to the maximum EQEs, because many articles do not give sufficient data concerning EQE at the practically relevant luminance of $100 \mathrm{~cd} / \mathrm{m}^{2}$.

\section{Review}

\section{Molecular design rules to produce a delayed fluorescence}

The efficiency of OLEDs is intimately related to the ability of the light-emitting materials to convert a maximum of injected charges into photons. To optimize this, the TADF process is the most promising strategy as it allows converting the generated and lost triplet excitons of the classical fluorescent materials into emissive singlets. By efficiently upconverting the triplet excitons from the triplet $\left(\mathrm{T}_{1}\right)$ to the singlet state $\left(\mathrm{S}_{1}\right)$, the intrinsic limitation of $25 \%$ imposed to fluorescent materials by the 1:3 singlet-triplet ratio can be overcome and an ultimate IQE of $100 \%$ can be realized with TADF materials. To promote the endothermic RISC, the energy gap between $S_{1}$ and $T_{1}$ $\left(\Delta E_{\mathrm{ST}}\right)$ plays a key role and should be as small as possible. From a molecular design viewpoint, $\Delta E_{\mathrm{ST}}$ can be drastically reduced if the highest occupied molecular orbital (HOMO) and the lowest unoccupied molecular orbital (LUMO) are spatially separated, what can be obtained by a suitable steric hindrance that introduces an internal twist and interrupts the $\pi$-conjugation but also by a sufficient distance between the electron-donating and the electron-accepting moieties [22-25]. In the design of TADF materials, it should be mentioned the major importance of the spin-orbit vibronic coupling, in addition to the small $\Delta E_{\mathrm{ST}}$. Indeed, a small $\Delta E_{\mathrm{ST}}$ is not sufficient to ensure for a TADF material an efficient RISC which is a vibronically coupled, spin-orbit coupling process with the involvement of the charge transfer state. To remain efficient, the spin-orbit coupling should still have a significant value, even if the separation of the HOMO and LUMO wavefunctions remain a requirement to minimize $\Delta E_{\mathrm{ST}}$. At present, systematic investigations examining the correlation between the spin-orbit coupling and RISC are still scarce [26-29]. Considering that the singlet-triplet energy splitting is one of the key elements for controlling the RISC efficiency, that the dihedral angle between the donor and the acceptor can be difficultly anticipated and that an overlap of both the HOMO/LUMO energy levels could adversely affect the color purity and $\Delta E_{\mathrm{ST}}$, it has to be noticed that the photophysical properties and the geometry of molecules that are suspected to be TADF emitters are often investigated by theoretical calculations prior to synthesis, optimizing the chance to get suitable energy levels and the desired $\Delta E_{\mathrm{ST}}$. This strategy was notably applied to the design of TADF blue emitters containing triarylboron accepting units. Besides, as we will see in this review, the design of a good TADF material by optimizing its structure by theoretical calculations is not sufficient to ensure the fabrication of highly emissive OLEDs. As observed for phosphorescent emitters, optimization of the device stacking, an appropriate choice of the host as well as the materials in the adjacent layers, an adequate dopant concentration, and the efficient confinement of excitons within the emissive layer are primordial parameters to elaborate high performance OLEDs while maintaining the color purity [30]. Due to the difficulty to address simultaneously these different points, numerous light emitting materials have been revisited several times, providing different electrical and optical device characteristics.

\section{Boron-containing TADF emitters}

Boron-containing molecules have been extensively investigated in organic electronics [31] as these materials are characterized by a remarkable electron mobility resulting from the presence of a vacant p-orbital on the boron atom $[32,33]$. Triarylboron compounds are also strong electron acceptors, justifying that numerous groups developed TADF emitters using triarylboron moieties as acceptors. As possible donors, diarylamines have often been proposed (carbazole, triphenylamine, carbazole/triphenylamine hybrids, 9,9-dimethyl-9,10-dihydroacridine), as exemplified in Figure 2 [34-36]. In B1 and B2, isolation of the two parts was obtained by linking the $10 H$-phenoxaborin unit or the dimesitylphenylboron moiety to the 9,9-dimethyl-9,10-dihydroacridine part through a phenylene bridge substituted at the 1,4-positions. By mean of steric repulsions occurring between the hydrogen atoms of the aromatic $\pi$-bridge and those of the neighbouring electron-donating and accepting parts, an effective spatial separation of the HOMO and LUMO levels could be obtained, resulting in the rotation of the two end-groups relative to the plane of the central aromatic ring. A dihedral angle of $51.8^{\circ}$ was found between the phenylene and the $10 \mathrm{H}$-phenoxaborin unit in $\mathbf{B 1}$, increasing to $88.4^{\circ}$ for the dihedral angle between the phenylene and the 9,9-dimethylacridane unit in $\mathbf{B 2}$. $\Delta E_{\mathrm{ST}}$ values of $0.013 \mathrm{eV}$ and $0.041 \mathrm{eV}$ were experimentally de- 
<smiles>CC1(C)c2ccccc2N(c2ccc(B3c4ccccc4Oc4ccccc43)cc2)c2ccccc21</smiles>

B1<smiles>c1ccc(N(c2ccccc2)c2ccc3[nH]c4ccccc4c3c2)cc1</smiles><smiles>Cc1cc(C)c(B2c3c(C)cc(C)cc3Cc3cc(N)cc(C)c32)c(C)c1</smiles>

B5<smiles>Cc1cc(C)c(B(c2ccc(N3c4ccccc4C(C)(C)c4ccccc43)cc2)c2c(C)cc(C)cc2C)c(C)c1</smiles><smiles>Cc1cc(C)c(B(c2c(C)cc(C)cc2C)c2c(C)cc(N3c4ccccc4C(C)(C)c4ccccc43)cc2C)c(C)c1</smiles>

B3<smiles>Cc1cc(C)c(B(c2c(C)cc(C)cc2C)c2c(C)cc(-n3c4ccc(N(c5ccccc5)c5ccccc5)cc4c4cc(N(c5ccccc5)c5ccccc5)ccc43)cc2C)c(C)c1</smiles>

B4<smiles></smiles>

B6<smiles>Cc1cc(C)c2c(c1)c1cc(C)cc(C)c1n2-c1ccc2c(C)c1B2c1ccccc1Oc1cc(C(C)C)cc(C(C)C)c1C(C)C</smiles><smiles>[R]c1ccccc1B(c1c(C)cc(C)cc1C)c1c(C)cc(C)cc1C</smiles>

with $\mathrm{R}=$<smiles></smiles>

B7

B8

\begin{tabular}{|c|c|c|c|c|c|c|c|c|}
\hline & B1 & B2 & B3 & B4 & B5 & B6 & B7 & B8 \\
\hline reference & {$[34]$} & {$[35]$} & {$[37]$} & {$[37]$} & {$[37]$} & {$[38]$} & {$[38]$} & {$[36]$} \\
\hline$\Delta E_{\mathrm{ST}}(\mathrm{eV})$ & 0.013 & 0.041 & 0.071 & 0.058 & 0.062 & 0.060 & 0.012 & 0.150 \\
\hline $\begin{array}{c}\text { decay time } \\
\text { delayed component }(\mu \mathrm{S})\end{array}$ & 2.36 & 6.71 & - & - & - & - & - & - \\
\hline $\mathrm{EQE}(\%)$ & 15.1 & 16.0 & 22.8 & 21.6 & 14.0 & 19.0 & 20.1 & 24.1 \\
\hline $\mathrm{CIE}(\mathrm{x}, \mathrm{y})$ or $\lambda_{\mathrm{EL}}(\mathrm{nm})$ & 466 & $(0.14,0.24)$ & $(0.22,0.55)$ & $(0.18,0.43)$ & $(0.17,0.30)$ & $(0.14,0.16)$ & $(0.140 .30)$ & $(0.14,0.20)$ \\
\hline
\end{tabular}

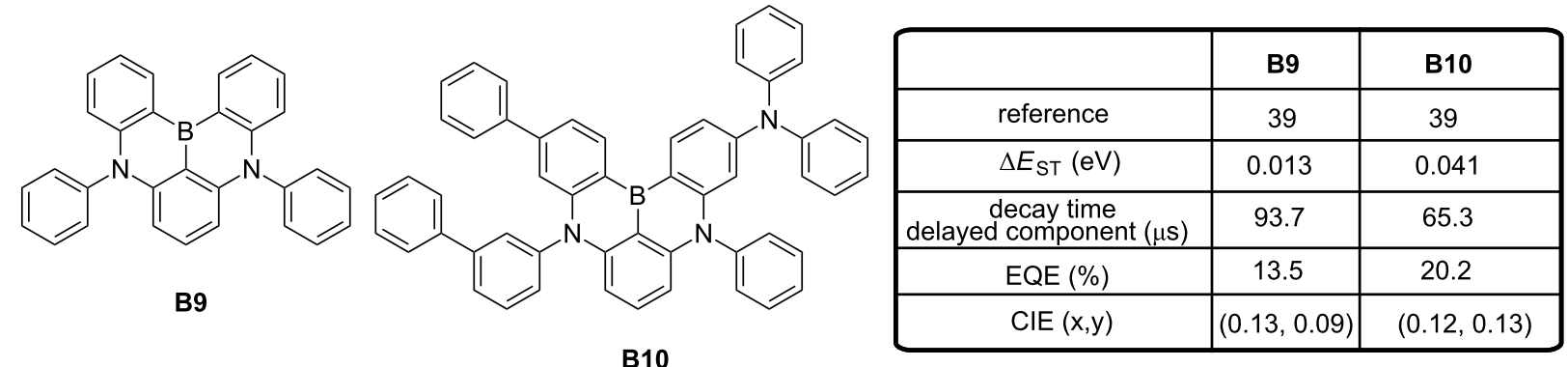

Figure 2: Boron-containing TADF emitters B1-B10.

termined for $\mathbf{B} \mathbf{1}$ and $\mathbf{B 2}$, respectively, calculated from the difference existing between the onset of the fluorescence and the phosphorescence emission. The decay time of the delayed component of luminescence was determined as being $2.36 \mu \mathrm{s}$ and $6.71 \mu$ s for B1 and B2, respectively. When evaluated in multilayered OLEDs, a blue electroluminescence (EL) peaking at $466 \mathrm{~nm}$ and $479 \mathrm{~nm}$, an external quantum efficiency (EQE) of $15.1 \%$ and $16.0 \%$ were obtained for $\mathbf{B} 1$ and $\mathbf{B 2}$, respectively, 
indicating the substantial contribution of the triplet excitons to the luminescence.

Interestingly, compared to $\mathbf{B} 2$, the introduction of two additional methyl groups in the phenyl part (B3) resulted in a clear bathochromic shift of the EL, OLEDs emitting a green light peaking at $502 \mathrm{~nm}$ [37]. A blue shift of the emission and skyblue OLEDs could only be obtained with this acceptor by replacing the electron-donating 9,9-dimethyl-9,10-dihydroacridinyl unit of $\mathbf{B 3}$ by a bis(diphenylamino)carbazole group in $\mathbf{B 4}$ or a diphenylaminocarbazole unit in B5. The outstanding EQE of $21.6 \%$ could be attained for the sky-blue B4-based devices. Still based on the combination of acridan and $10 \mathrm{H}$ phenoxaborin units, a complete isolation of the two units could be realized in $\mathbf{B 6}$ by directly functionalizing the $10 \mathrm{H}$-phenoxaborin core with a spiro-type acridan group [38]. Using this strategy, pure blue OLEDs exhibiting an EQE of $19.0 \%$ and Commission Internationale de l'Eclairage (CIE) coordinates of $(0.14,0.16)$ were obtained with B6. Comparable performances were determined for B7 $(20.1 \%$, $(0.14,0.16))$, comprising the sterically demanding tetramethylcarbazole. In these two structures, a large dihedral angle arising from steric repulsions between hydrogen atoms in the peri-position of $\mathbf{B 6}$ and from the presence of methyl groups at the 3,6-positions of 1,3,6,8-tetramethylcarbazole in $\mathbf{B} 7$ could be obtained. In fact, the substitution at the 3,6-position of carbazole could maintain a large dihedral angle in $\mathbf{B} 7$ whereas the two methyl groups at the 1,8-positions were introduced for a higher electrochemical stability of the carbazole donor. Finally, by modifying the connectivity between the donor and acceptor in $\mathbf{B 8}$, a record-high EQE of $24.1 \%$ could be realized for pure-blue OLEDs $(0.139,0.150)$ close to the National Television Standards Committee standard (NTSC) blue values of $(0.14,0.08)$ [36]. Upon ortho-substitution of the dimesitylphenylboron acceptor with a carbazole, a mutual steric hindrance could be exerted between the donor and the acceptor resulting in the large dihedral angle of $72.6^{\circ}$. A $\mathrm{S}_{1}-\mathrm{T}_{1}$ energy splitting of $0.13 \mathrm{eV}$ could be also experimentally determined for B8. Interestingly, the outstanding EL characteristics of B8-based devices were assigned to the large contribution of the delayed fluorescence $(61 \%)$ in the overall luminescence decay of B8. A pure blue emission could also be realized by totally blocking the structure, what was done with $\mathbf{B 9}$ and $\mathbf{B 1 0}$ in which two of the three aromatic rings of triphenylamine were connected to the boron center [39]. By elongating the $\pi$-conjugation of the electron-donating group in $\mathbf{B 1 0}$ compared to $\mathbf{B 9}$, a more delocalized HOMO level could be generated, resulting in a greater intramolecular charge transfer and an increase of the oscillator strength. As a result, EQE of corresponding OLEDs increased from $13.5 \%$ (459 nm, $(0.13,0.09))$ for B9-based devices to $20.2 \%$ (467 nm, $(0.12,0.13)$ ) for B10based devices. If the electron-to-photon conversions are remark- able, none of the OLEDs could reach the brightness of $1000 \mathrm{~cd} / \mathrm{m}^{2}$ owing to a dramatic efficiency roll-off. Precisely, the efficiency roll-off determined for B9- and B10-based devices was determined as originating from an imbalanced charge transportation and the presence of bimolecular quenching processes occurring at high current density such as triplet-triplet annihilation and exciton-polaron annihilation.

\section{Diphenylsulfone-based emitters}

Concerning the design of blue TADF emitters, diphenylsulfone is the third most widely studied acceptor in the literature, followed by triarylboron and triazine derivatives. In this field, the contribution of the Adachi's group is remarkable. The first report mentioning a pure blue emission with a diphenylsulfone derivative was reported in 2012 [40]. By a careful control of the $\pi$-conjugation length between the donor and the acceptor, D3-based OLEDs producing a deep blue emission with CIE coordinates of $(0.15,0.07)$ were fabricated (see Figure 3$)$. Examination of the phosphorescence spectra of D1-D3 at $77 \mathrm{~K}$ revealed their $\mathrm{T}_{1}$ states to be ${ }^{3} \pi \pi^{*}$ states centred on their electron-donating parts. $\Delta E_{\mathrm{ST}}$ values of $0.54,0.45$ and $0.32 \mathrm{eV}$ were, respectively, determined for D1-D3. Changes in $\Delta E_{\mathrm{ST}}$ were explained as follow: By introducing tert-butyl groups on the diphenylamine unit, the electron donating ability in D2 was reinforced compared to D1, red-shifting the charge transfer (CT) band and lowering the CT energy as well as $\Delta E_{\mathrm{ST}}$. By replacing the diphenylamine unit of $\mathbf{D 1}$ by a tert-butyl-substituted carbazole unit in D3, the ${ }^{3} \pi \pi^{*}$ state was considerably destabilized, raising its energy level and decreasing $\Delta E_{\mathrm{ST}}$. Parallel to this, a greater separation of the HOMO and LUMO orbitals was evidenced by theoretical calculations for D3, as a result of a larger dihedral angle $\left(49^{\circ}\right.$ instead of $32^{\circ}$ for D1 and D2), resulting in a smaller energy difference between the singlet and triplet excited states. As expected, the contribution of the slow decay component in the luminescence of D1-D3 decreased with increasing $\Delta \mathrm{E}_{\mathrm{ST}}$, almost disappearing for $\mathbf{D} 1$. While using D1-D3 as dopants for multilayer OLEDs, maximum EQEs of OLEDs coincide the order previously determined for the proportion of the delayed component in the total emission of D1-D3 with the EQE (D1) < EQE (D2) < EQE (D3) $(2.9 \%, 5.6 \%$ and $9.9 \%$ for D1-D3, respectively). If D3 displayed the best EQE for the series, a dramatic efficiency rolloff at high current density was observed, as the result of a long TADF lifetime $(270 \mu$ s). This issue was addressed with D4 [41]. By replacing the tert-butyl groups of $\mathbf{D 3}$ by methoxy groups in D4, a significant decrease of $\Delta E_{\mathrm{ST}}$ was obtained $(0.21 \mathrm{eV}$ instead of $0.32 \mathrm{eV}$ for D3), reducing the TADF lifetime and efficiency roll-off. More precisely, the higher electron-donating ability and the longer conjugation length of the 3,6-dimethoxycarbazole compared to the 3,6-di-tert-butylcarbazole lowered the $S_{1}$ state and to a greater extend the $T_{1}$ state of $\mathbf{D 4}$, 


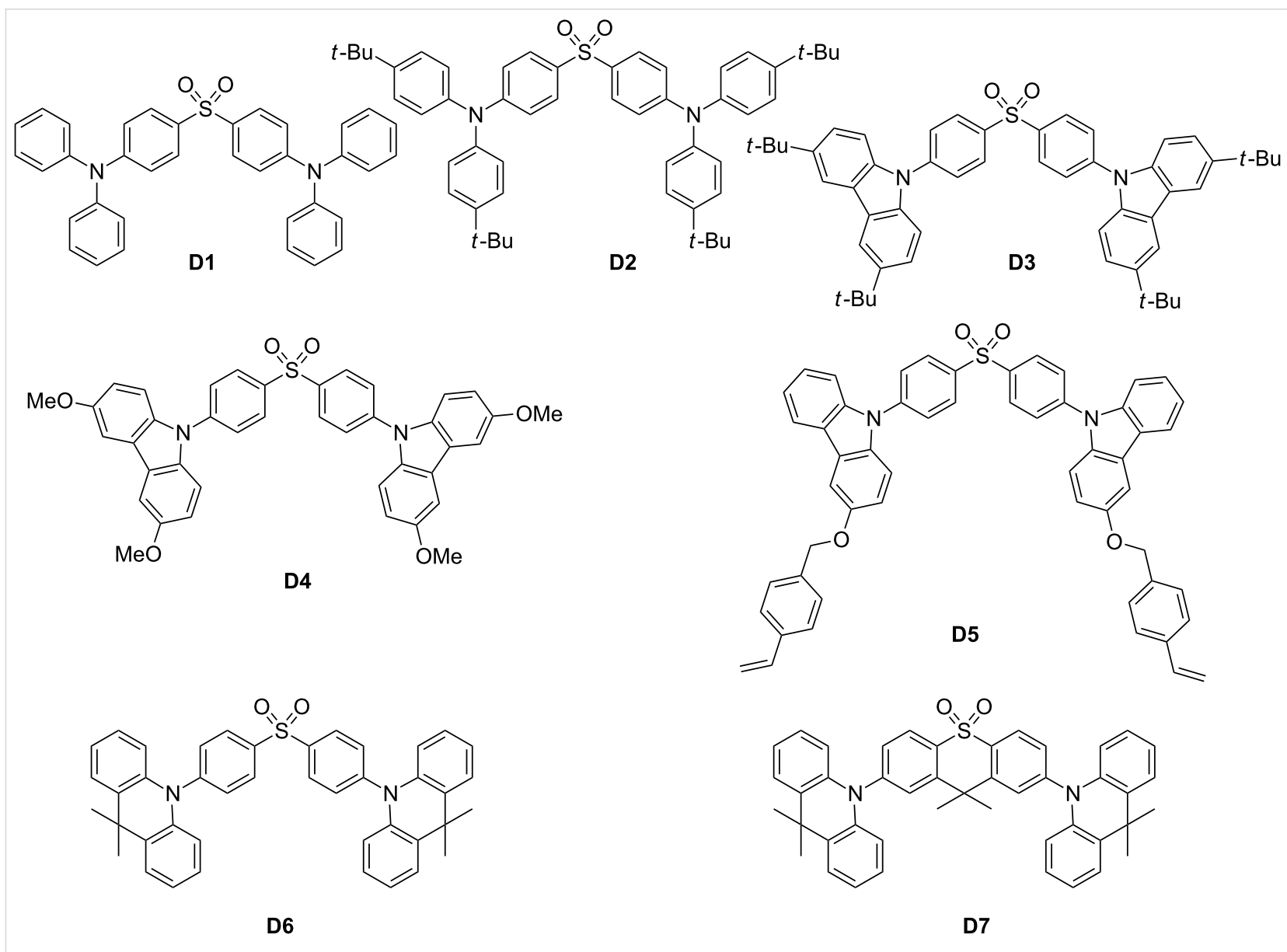

\begin{tabular}{|c|c|c|c|c|c|c|c|}
\hline & D1 & D2 & D3 & D4 & D5 & D6 & D7 \\
\hline reference & {$[40]$} & {$[40]$} & {$[40]$} & {$[41]$} & {$[42]$} & {$[43]$} & {$[29]$} \\
\hline$\Delta E_{\mathrm{ST}}(\mathrm{eV})$ & 0.54 & 0.45 & 0.32 & 0.21 & 0.31 & 0.08 & 0.15 \\
\hline $\begin{array}{c}\text { decay time } \\
\text { delayed component }(\mu \mathrm{s})\end{array}$ & 90 & 140 & 270 & 93 & 50 & 7 & 44 \\
\hline $\mathrm{EQE}(\%)$ & 2.9 & 5.6 & 9.9 & 14.5 & 2.0 & 19.5 & 22.4 \\
\hline $\mathrm{CIE}(\mathrm{x}, \mathrm{y})$ or $\lambda_{\mathrm{EL}}(\mathrm{nm})$ & 421 & 430 & $(0.15,0.07)$ & $(0.16,0.16)$ & $(0.12,0.13)$ & $(0.16,0.20)$ & $(0.16,0.24)$ \\
\hline
\end{tabular}

Figure 3: Diphenylsulfone-based TADF emitters D1-D7.

furnishing in turn a molecule with a smaller $\Delta E_{\mathrm{ST}}$ than $\mathbf{D 3}$. Jointly, due to the reduction of $\Delta E_{\mathrm{ST}}$, a TADF lifetime of $93 \mu \mathrm{s}$ was determined for D4, far from the value measured for D3 $(270 \mu \mathrm{s})$. When tested in a similar device structure than that previously used for D3, a maximum EQE of $14.5 \%$ and a smaller efficiency roll-off was evidenced for D4-based devices, attributed to the smaller $\Delta E_{\mathrm{ST}}$ and the shorter TADF lifetime. Recently, a thermally cross-linkable and solution-processable version of D4, i.e., D5 was reported in the literature [42]. If the strategy is appealing, the final EL performances of D5-based OLEDs were far from that obtained with vacuum-processed OLEDs and a maximum EQE of only $2.0 \%$ could be reached.
Following the basic rule of molecular design consisting in maximizing the dihedral angle to minimize $\Delta E_{\mathrm{ST}}$, substitution of diphenylsulfone by 9,9-dimethyl-9,10-dihydroacridine resulting in an almost orthogonality of the two groups in D6 as a dihedral angle as large as $89^{\circ}$ could be determined between 9,9dimethyl-9,10-dihydroacridine and the connected phenyl ring of the diphenylsulfone unit [43].

A significant reduction of the TADF lifetime $(\approx 7 \mu \mathrm{s})$ and a small $\Delta E_{\mathrm{ST}}$ of $0.08 \mathrm{eV}$ were measured for $\mathbf{D 6}$, favorable to the fabrication of highly emissive blue OLEDs. Devices fabricated with D6 furnished a maximum EQE of $19.5 \%$ and maintained 
the high EQE of $16 \%$ at $1000 \mathrm{~cd} / \mathrm{m}^{2}$ with a satisfactory color purity of coordinates $(0.16,0.20)$. Recently, high-performance TADF based hybrid WOLEDs employing D6 as the blue emitter were successfully fabricated [44]. Interestingly, WOLEDs showed excellent device characteristics with an EQE of $23.0 \%$, a current and power efficiency of $51.0 \mathrm{~cd} / \mathrm{A}$ and $51.7 \mathrm{~lm} / \mathrm{W}$, respectively. These performances are among the highest values reported to date for hybrid WOLEDs using a TADF material as the blue emitter. Derivative D6 was also examined in the context of undoped OLEDs [45]. Undoped OLEDs are more attractive than their doped analogues due to an easier fabrication process, a higher reproducibility and reliability. With regards to the highly twisted structure of $\mathbf{D 6}$ and the presence of methyl groups on the 9,9-dimethyl-9,10-dihydroacridine units, this molecule proved to be also nearly insensitive to the concentration, showing an emission maximum for the neat film at $470 \mathrm{~nm}$ which is almost similar to that obtained for a $10 \mathrm{wt} \%$-doped $\mathrm{mCP}$ film (462 $\mathrm{nm}$ where $\mathrm{mCP}$ stands for $m$-bis( $N$-carbazolyl)benzene). Parallel to this, the fluorescence and TADF lifetime were almost the same for both the doped and undoped film, making D6 a candidate applicable for the design of undoped OLEDs. Trilayered undoped OLEDs fabricated with D6 displayed a sky-blue emission peaking at $480 \mathrm{~nm}$, with an EQE of $19.5 \%$ at a luminance of $100 \mathrm{~cd} / \mathrm{m}^{2}$, slightly red-shifted compared to the emission observed for doped OLEDs. Clearly, the specific design of D6 and its highly twisted structure efficiently weakened the $\pi-\pi$-stacking interactions, providing a general design rule for the elaboration of TADF emitters insensitive to the concentration. Belonging to the same family of structure than D6, D7 that derives from the 9,9-dimethylthioxanthene-S,S-dioxide structure provided a better color purity $(465 \mathrm{~nm},(0.16,0.24)$ for D7 instead of $480 \mathrm{~nm}$ for D6) and a higher EQE (22.4\% for D7 instead of $19.5 \%$ for D6) than D6 by optimizing the architecture of the doped EML [29]. By selecting the host of appropriate polarity, the combination of $\mathbf{D} 7$ with the correct host could minimize the RISC barrier, optimize the RICS rate and thus maximize the TADF efficiency. While combining the blue TADF emitter D7 with a green and an orange TADF emitter, all-TADF white OLEDs with 16\% EQE could be fabricated [30].

\section{Triazine-pyrimidine based emitters}

Among possible electron acceptors, another structure has been extensively regarded as an adequate electron acceptor for the design of blue TADF emitters and this structure is the triazine unit. When combined with the azasiline donor, OLEDs displaying the unprecedented EQE of $22.3 \%$ were obtained [46]. As specificity, azasiline is a 6-membered heterocycle comprising a silicon atom introduced instead of a carbon atom to enlarge the HOMO-LUMO gap and lower the HOMO level. Due to the $\mathrm{sp}^{3}$ hybridization of the silicon atom, two phenyl rings can be introduced on the silicon-bridged structure providing bulkiness and rigidity to the donor. Intermolecular interactions are thus efficiently prevented and the conformation disorder drastically reduced. When used as electron donor in T1, a $\Delta E_{\mathrm{ST}}$ of $0.14 \mathrm{eV}$ was determined experimentally, with a TADF lifetime of $25.4 \mu$ s and a 13:87 ratio between the prompt and delayed fluorescence. OLEDs fabricated with $\mathbf{T 1}$ and a mCP:TSPO1 cohost (with TSPO1 = diphenyl-4-(triphenylsilyl)phenylphosphine oxide) furnished a blue emission peaking at $463 \mathrm{~nm}$, with CIE coordinates of $(0.149,0.197)$ and a low efficiency roll-off. Another key and general design rule for obtaining a small $\Delta E_{\mathrm{ST}}$ consists in the physical separation of the donor and the acceptor by elongating the spacer that couples the two partners. Following this recommendation, an additional phenyl ring was introduced between the donor and the acceptor in T2, providing the extended version of T1 (see Figure 4) [47]. As expected, the phenyl ring increased the separation of the HOMO and LUMO orbitals, such that $\Delta E_{\mathrm{ST}}$ decreased. A value as low as $0.04 \mathrm{eV}$ was experimentally determined for T2. In doped devices, $\mathbf{T} 2$ demonstrated an EL efficiency of $4.7 \%$ with a deep blue emission $(0.151,0.087)$ approaching the NTSC blue standard $(0.14,0.08)$. However, a comparison with the previous EL performance evidenced that EQEs obtained with $\mathbf{T} 2$ are 5 times lower than that obtained with T1, despites the more favorable $\mathrm{S}_{1}-\mathrm{T}_{1}$ energy splitting. This problem is commonly observed if the isolation of the electron-donating and electronaccepting parts is obtained upon extension of the distance between the two moieties. Indeed, as a consequence of this strategy, a weaker intramolecular charge transfer takes place and a reduction of the oscillator strength in the D-A diad is observed, resulting in a drastic reduction of the PLQY and thus of the external quantum efficiency. In the same study, authors examined the case of two TADF emitters based on a donor-acceptor-donor (D-A-D) structure, i.e., T3 and T4, where azasiline was used as the donor and diphenylsulfone or benzophenone as the acceptors. Here again, the higher twisted molecular structure of $\mathbf{T} 4$ was beneficial in terms of $\Delta E_{\mathrm{ST}}$, color purity and EL performances. Thus, the higher internal torsion of T4 furnished OLEDs with a deeper blue emission $(0.154,0.107)$ than devices fabricated with $\mathbf{T} 3(0.174,0.310)$. Even if the EQE of T4-based devices was lower than that of T3-based devices (2.3\% for T4-based OLEDs instead of $11.4 \%$ for T3-based devices), it is attributable to the higher color purity of T4-based devices and not to differences of $\Delta E_{\mathrm{ST}}$ ( $0.07 \mathrm{eV}$ and $0.06 \mathrm{eV}$ for $\mathbf{T 3}$ and $\mathbf{T 4}$, respectively). Azasiline is a promising electron donor but examples of blue TADF emitters are still scarce. The opposite situation is found for carbazole, which has long been considered as an excellent donor and a large variety of blue TADF emitters have been designed on the basis of this scaffold. At least 19 examples of blue TADF emitters can be cited, the molecules differing by the 
<smiles>c1ccc(-c2nc(-c3ccccc3)nc(-c3ccc(N4c5ccccc5[Si](c5ccccc5)(c5ccccc5)c5ccccc54)cc3)n2)cc1</smiles>

T1<smiles></smiles>

T2<smiles>O=C(c1ccc(N2c3ccccc3[Si](c3ccccc3)(c3ccccc3)c3ccccc32)cc1)c1ccc(N2c3ccccc3[Si](c3ccccc3)(c3ccccc3)c3ccccc32)cc1</smiles><smiles>O=S(=O)(c1ccc(N2c3ccccc3[Si](c3ccccc3)(c3ccccc3)c3ccccc32)cc1)c1ccc(N2c3ccccc3[Si](c3ccccc3)(c3ccccc3)c3ccccc32)cc1</smiles><smiles></smiles>

T5<smiles></smiles><smiles></smiles>

T7

\begin{tabular}{|c|c|c|c|c|c|c|c|c|}
\hline & T1 & T2 & T3 & T4 & T5 & T6 & T7 & T7 \\
\hline reference & {$[46]$} & {$[47]$} & {$[47]$} & {$[47]$} & {$[48]$} & {$[48]$} & {$[48]$} & {$[49]$} \\
\hline$\Delta E_{\text {ST }}(\mathrm{eV})$ & 0.14 & 0.04 & 0.06 & 0.07 & 0.09 & 0.09 & 0.28 & 0.35 \\
\hline $\begin{array}{c}\text { decay time } \\
\text { delayed component }(\mu \mathrm{s})\end{array}$ & 25.4 & - & - & - & - & - & - & - \\
\hline $\mathrm{EQE}(\%)$ & 22.3 & 4.7 & 11.4 & 2.3 & 7.7 & 20.6 & 16.8 & 12.2 \\
\hline $\mathrm{CIE}(\mathrm{x}, \mathrm{y})$ & $(0.15,0.20)$ & $(0.15,0.09)$ & $(0.17,0.31)$ & $(0.15,0.11)$ & $(0.26,0.43)$ & $(0.19,0.35)$ & $(0.170 .27)$ & $(0.18,0.32)$ \\
\hline
\end{tabular}

Figure 4: Triazine-based TADF emitters T1-T3, T5-T7 and azasiline derivatives T3 and T4.

strategy used to connect the donor(s) to triazine. However, contrarily to azasiline that possesses a six-membered central ring, carbazole only possesses a five-membered central ring, inducing a deviation of the two adjacent aromatic rings. As a result, carbazole is not capable to induce the same encumbrance as that of azasiline by inducing smaller steric effects and the substitution of the 1,8-positions is often required to maintain a large dihedral angle.
As interesting design rules, Adachi determined that the extension of the electronic delocalization of both the HOMO and LUMO energy levels could greatly increase the rate of the radiative decay by inducing a large oscillator strength while lowering $\Delta E_{\mathrm{ST}}$, even for emitters for which only a small overlap between the two wavefunctions is observed [48]. These findings constitute a second guideline for the molecular design of TADF emitters that can address the distance and the reduction 
of the oscillator strength issue previously mentioned. To establish this, a series of molecules T5-T8 with varying length of the $\pi$-conjugated system for the donating part was investigated. Thus, for T5 and T6, a similar $\Delta E_{\mathrm{ST}}$ value of $0.09-0.12 \mathrm{eV}$ was experimentally determined for the two emitters. However, significant differences were determined for their PLQYs and values of 0.1 and 0.7 were measured for $\mathbf{T 5}$ and T6, respectively. By theoretical calculations, the oscillator strength of T6 was found to be 13.6 times greater than that of $\mathbf{T 5}$, supporting the enhanced luminescence of $\mathbf{T} \mathbf{6}$ by the higher delocalization of its HOMO level. This trend was confirmed by keeping the acceptor constant in T6-T8. An increase of $\Delta E_{\mathrm{ST}}$ while reducing the possible electronic delocalization over the electron-donating part was clearly evidenced going from T6 to T8. In OLEDs, EL performances followed the same trend, with the highest EQE obtained with $\mathbf{T 6}(\mathrm{EQE}=20.6 \%)$ and the lowest one with $\mathbf{T 8}$ $(\mathrm{EQE}=14.6 \%)$. A lower color purity was obtained for T6-based devices $\left(\lambda_{\mathrm{EL}}=487 \mathrm{~nm}\right)$ compared to $\mathbf{T} 7$ and $\mathbf{T 8}$ ( $\lambda_{\mathrm{EL}}=478$ and $477 \mathrm{~nm}$, respectively) [22]. A worse result was obtained for $\mathbf{T} 5$ that produced a blue-green EL at $506 \mathrm{~nm}$. Recently, an extensive work was devoted to examine the degradation mechanisms in blue TADF OLEDs and $\mathbf{T} 7$ was revisited in this context [49]. The synergy of an electro-oxidation process together with a photo-oxidation was determined as playing a critical role in the degradation of blue TADF emitters. In fact, a parallel can be easily done with the treatment of wastewater, where pollutants are removed from water by combining a photochemical and an electrochemical process [50]. During this study, the localization of the triplet spin density was found determinant for the stability of blue TADF emitters. To evidence this, four emitters (T7, T9-T11) exhibiting the same $S_{1}$ and $\mathrm{T}_{1}$ energy levels, the same TADF lifetimes but differing by the distribution of the triplet spin densities were examined (see Figure 4 and Figure 5). Notably, for T9, the triplet spin density was found to be mainly localized on the bicarbazole donor, whereas for $\mathbf{T} 7$ and $\mathbf{T 1 0}$, the triplet spin density is localized on their acceptor fragment. To end, the triplet spin density of T11 is delocalized over the entire structure. While examining the device lifetime, T9-based devices had the longest device lifetime (32 hours), far from T10-, T7- and T11-based OLEDs ( $1.4 \mathrm{~h}, 2.8 \mathrm{~h}$ and $0.9 \mathrm{~h}$, respectively), demonstrating the higher stability of the emitters with a triplet spin density centered onto the donor unit. In another study, an analogue of T9, i.e., T12, differing by the removal of a phenyl ring between the carbazole and the triazine units proved once again the crucial role of the oscillator strength in the photophysical properties [51]. Notably, major differences in the separation of their HOMO and LUMO energy levels were determined by theoretical calculations. An overlap of the two electronic wavefunctions was detected for T9 whereas the two orbitals are strongly localized in the case of T12. Resulting from this marked localization in T12, a smaller variation of the electronic density upon excitation is expected, reducing the oscillator strength and the PLQY. When tested in devices, only a green-blue emission was obtained with T12 (see Figure 5) [52]. The Influence of the oscillator strength on OLEDs characteristics could also be evidenced while comparing T13 and T14 [53]. Molecular orbital calculations performed on T13 and T14 showed the two molecules to exhibit a similar electronic distribution, what was confirmed by UV-visible and photoluminescence (PL) spectroscopy. Only a slight red shift of the absorption was detected for T14 as the result of the strengthened donating ability of the dicarbazolylphenyl moieties. Similarly, almost identical $\Delta E_{\mathrm{ST}}$ were determined with values of 0.25 and $0.27 \mathrm{eV}$ for T13 and T14, respectively). As it could be anticipated, T14 furnished slightly better EL performances (18.9\%) compared to that measured for T13 (17.8\%), due to its more extended donating part but also owing to its higher PLQY. Conversely, the color purity was higher for T13-based devices ( $\lambda_{\mathrm{EL}}=459 \mathrm{~nm}$ ) instead of $467 \mathrm{~nm}$ for T14-based devices. However, a remarkable device stability was demonstrated for T14-based OLEDs, $80 \%$ of the initial luminance being retained after 52 hours. This value was reduced to only 5 hours for T13-based OLEDs. A comparison established with an iridium complex, i.e., tris[1(2,4-diisopropyldibenzo[ $b, d]$ furan-3-yl)-2-phenyl- $1 H$-imidazole]iridium(III) (Ir(dbi) $)_{3}$ ) evidenced the relevance of the TADF approach, as a device lifetime of only 18 hours was found while operating OLEDs in the same conditions. The spatial separation of the electron-donating part from the electron-accepting moiety by elongating the spacer has already been discussed and the drawbacks evoked.

Minimization of the electron density overlap can also be realized by means of an ortho-phenyl linkage, enabling to maintain the donor in proximity of the acceptor.

In this situation, one aromatic ring of the donor and/or the acceptor is substituted at the 1,2-positions, generating a highlytwisted structure. Five blue TADF emitters T15-T19 were designed on this basis (see Figure 6). By increasing the number of carbazoles in $\mathbf{T 1 6}$ compared to $\mathbf{T 1 5}$, a decrease of $\Delta E_{\mathrm{ST}}$ was logically observed (0.06 eV for T15 and $0.03 \mathrm{eV}$ for T16) [54]. A large torsion angle of $66^{\circ}$ and $67^{\circ}$ were, respectively, determined by theoretical calculations for T15 and T16, favorable to the separation of the two orbitals. In devices, a remarkable enhancement of the EL performances was realized by increasing the number of carbazole units. Thus, a maximum EQE of $12.2 \%$ was realized with T15, whereas an EQE of $16.5 \%$ was determined for T16-based devices.

This enhancement can also be attributable to an increase of the oscillator strength from T15 to T16, the number of donors 


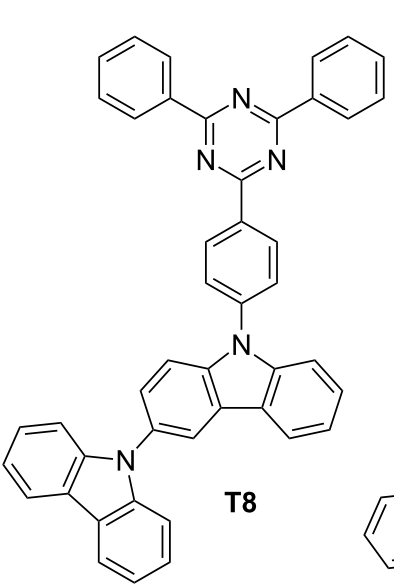<smiles></smiles><smiles>C=CC=CC(C)=CC=C</smiles><smiles>c1ccc(-c2nc(-c3ccccc3)nc(-c3cc(-n4c5ccccc5c5ccccc54)cc(-n4c5ccccc5c5ccccc54)c3)n2)cc1</smiles>

T13<smiles>c1ccc(-c2nc(-c3ccccc3)nc(-c3ccc(N4c5ccccc5C(c5ccccc5)(c5ccccc5)c5ccccc54)cc3)n2)cc1</smiles>

T11<smiles></smiles>

\begin{tabular}{|c|c|c|c|c|c|c|c|}
\hline & T8 & T9 & T10 & T11 & T12 & T13 & T14 \\
\hline reference & {$[48]$} & {$[49]$} & {$[49]$} & {$[49]$} & {$[51]$} & {$[53]$} & {$[53]$} \\
\hline$\Delta E_{\text {ST }}(\mathrm{eV})$ & 0.32 & 0.31 & 0.38 & 0.28 & - & - & - \\
\hline $\begin{array}{c}\text { decay time } \\
\text { delayed component }(\mu \mathrm{s})\end{array}$ & - & - & - & - & - & 3.1 & 2.8 \\
\hline $\mathrm{EQE}(\%)$ & 14.6 & 20.5 & 11.8 & 18.2 & - & 17.8 & 18.9 \\
\hline $\mathrm{CIE}(\mathrm{x}, \mathrm{y})$ & $(0.18,0.28)$ & $(0.18,0.34)$ & $(0.21,0.39)$ & $(0.19,0.36)$ & - & $(0.15,0.16)$ & $(0.16,0.22)$ \\
\hline
\end{tabular}

Figure 5: Triazine-based TADF emitters T8, T9, T11-T14 and carbazole derivative T10.

being increased. The low efficiency roll-off of T16-based devices was assigned to the specific design of the emitter, with the triazine acceptor being totally surrounded by carbazoles. As a result, triplet-triplet annihilation by the Dexter mechanism could be efficiently prevented, enabling to maintain high efficiencies at high current density. Although the number of carbazole units increased, no modification of the EL position was detected, the emission peaking at 467 and $468 \mathrm{~nm}$ for T15and T16-based devices. In the same spirit, other authors examined the possible impact of the substitution pattern of the carbazole unit on the photophysical properties.
While maintaining the same number of carbazole units on the emitter and by varying the substitution pattern of the carbazole core, only a weak influence on the EL characteristics was evidenced [55]. In fact, performances only varied by their differences of PLQYs (16.7\%, 50.5\% and 43.0\% for T17, T18 and T19, respectively), the three molecules exhibiting similar photophysical properties $\left(\Delta E_{\mathrm{ST}}\right.$, emission wavelength and decay times of the delayed emission). Recently, a potential alternative to the ortho-substitution of the triazine acceptor by carbazole moieties was examined, consisting in introducing methyl groups in the proper position of the triazine or the carbazole moieties 
<smiles>c1ccc(-c2nc(-c3ccccc3-n3c4ccccc4c4ccccc43)nc(-c3ccccc3-n3c4ccccc4c4ccccc43)n2)cc1</smiles>

T15<smiles></smiles>

T16<smiles>c1ccc(-c2nc(-c3ccccc3)nc(-c3ccccc3-n3c4ccccc4c4ccccc43)n2)cc1</smiles>

T17

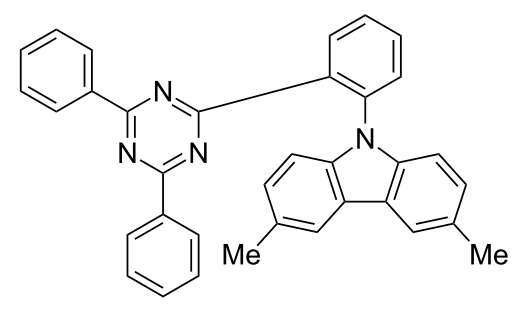

T18<smiles>CC(C)(C)c1ccc2c(c1)c1cc(C(C)(C)C)ccc1n2-c1ccccc1-c1nc(-c2ccccc2)nc(-c2ccccc2)n1</smiles>

T19

\begin{tabular}{|c|c|c|c|c|c|}
\hline & T15 & T16 & T17 & T18 & T19 \\
\hline reference & {$[54]$} & {$[54]$} & {$[55]$} & {$[55]$} & {$[55]$} \\
\hline$\Delta E_{\mathrm{ST}}(\mathrm{eV})$ & 0.06 & 0.03 & - & - & - \\
\hline $\begin{array}{c}\text { decay time } \\
\text { delayed component }(\mu \mathrm{s})\end{array}$ & 5.4 & 5.0 & 3.9 & 3.9 & 3.9 \\
\hline $\mathrm{EQE}(\%)$ & 12.2 & 14.9 & 9.3 & 14.7 & 12.3 \\
\hline $\mathrm{CIE}(\mathrm{x}, \mathrm{y})$ & $(0.15,0.21)$ & $(0.15,0.22)$ & $(0.15,0.22)$ & $(0.17,0.34)$ & $(0.17,0.31)$ \\
\hline
\end{tabular}

Figure 6: Triazine-based TADF emitters T15-T19.

[56]. By changing the methyl group positions, optical properties of T20-T23 were not significantly modified, contrarily to their $\Delta E_{\mathrm{ST}}$ (see Figure 7). In fact, the authors evidenced the introduction of methyl groups at the 1,8-positions of carbazole to be harmful for producing a deep-blue emission whereas the substitution of the central phenyl ring by methyl groups could provide the same molecular twist than the 1,8-substitution of carbazole while maintaining a large optical bandgap. In fact, dihedral angles of 49.9, 86.8, 71.4 and $82.4^{\circ}$ were determined by density functional theory (DFT) calculations between the donor plane and the acceptor plane for T20-T23, respectively. Due to its lesser twisted structure and based on the design rule previously evoked (orthogonality between the donor and the acceptor is researched to isolate the two groups), T20 showed the higher $\Delta E_{\mathrm{ST}}$ of the series. Theoretical calculations clearly evidenced for T20 the HOMO level to extend to the neighbouring phenylene bridge, adversely affecting $\Delta E_{\mathrm{ST}}$. Conversely, the large dihedral angle of T21-T23 contributed to spatially separate the HOMO from the LUMO orbitals. By electrochemistry, an appreciable reduction of the oxidation potential was detected $(+0.87 \mathrm{~V})$ for $\mathbf{T 2 1}$ which is substituted at the 1,8-positions of the donor whereas T20, T22 and T23 exhibited the same oxidation potentials $(+0.97 \mathrm{~V})$. By PL, $\mathrm{T}_{1}$ states of $\mathbf{T 2 0}$, $\mathbf{T 2 2}$ and $\mathbf{T 2 3}$ proved to be ${ }^{3} \mathrm{LE}$ states whereas a ${ }^{3} \mathrm{CT}$ state was found for $\mathbf{T} 21$.

To evidence this, examination of the phosphorescence spectra of T20-T23 in a frozen toluene matrix at $77 \mathrm{~K}$ revealed for T20, T22 and T23 to exhibit well-resolved vibrational structures, demonstrating their $\mathrm{T}_{1}$ states to be ${ }^{3} \mathrm{LE}$ states. Conversely, only a broad spectrum was obtained for T21, and its triplet state was assigned to a ${ }^{3} \mathrm{CT}$ state. Precisely, by its large dihedral angle, T21 differs from T20, T22 and T23 by the order of its orbitals, ${ }^{3} \mathrm{LE}$ and ${ }^{3} \mathrm{CT}$ being inverted in this case. Analysis of the transient PL decay curves showed T20 to exhibit a negligible delayed fluorescence as a result of large $\Delta E_{\mathrm{ST}}$. On the 
<smiles>Cc1ccc2c(c1)c1cc(C)ccc1n2-c1ccc(-c2nc(-c3ccccc3)nc(-c3ccccc3)n2)cc1</smiles>

T20<smiles>CC1(C)c2ccccc2N(c2ccc(-c3nc(-c4ccccc4)cc(-c4ccccc4)n3)cc2)c2ccccc21</smiles>

T24<smiles>Cc1cc(C)c2c(c1)c1cc(C)cc(C)c1n2-c1ccc(-c2nc(-c3ccccc3)nc(-c3ccccc3)n2)cc1</smiles>

T21<smiles>Cc1ccc2c(c1)c1cc(C)ccc1n2-c1ccc(-c2nc(-c3ccccc3)nc(-c3ccccc3)n2)cc1C</smiles>

T22<smiles>Cc1ccc2c(c1)c1cc(C)ccc1n2-c1c(C)cc(-c2nc(-c3ccccc3)nc(-c3ccccc3)n2)cc1C</smiles>

T23<smiles>CC1(C)c2ccccc2N(c2ccc(-c3cc(-c4ccccc4)nc(-c4ccccc4)n3)cc2)c2ccccc21</smiles><smiles>CC1(C)c2cc(-n3c4ccccc4c4ccccc43)ccc2N(c2ccc(-c3cc(-c4ccccc4)nc(-c4ccccc4)n3)cc2)c2ccc(-n3c4ccccc4c4ccccc43)cc21</smiles>

T26

\begin{tabular}{|c|c|c|c|c|c|c|c|}
\hline & T20 & T21 & T22 & T23 & T24 & T25 & T26 \\
\hline reference & {$[56]$} & {$[56]$} & {$[56]$} & {$[56]$} & {$[57]$} & {$[57]$} & {$[57]$} \\
\hline$\Delta E_{\text {ST }}(\mathrm{eV})$ & 0.43 & 0.07 & 0.17 & 0.15 & 0.25 & 0.17 & 0.12 \\
\hline $\begin{array}{c}\text { decay time } \\
\text { delayed component }(\mu \mathrm{s})\end{array}$ & - & 3.5 & 13.0 & 10.3 & 178 & 87 & 55 \\
\hline $\mathrm{EQE}(\%)$ & 7.2 & 22.0 & 19.2 & 18.3 & 11.8 & 18.6 & 22.8 \\
\hline $\mathrm{CIE}(\mathrm{x}, \mathrm{y})$ & - & - & $(0.15,0.10)$ & $(0.15,0.10)$ & $(0.16,0.21)$ & $(0.18,0.33)$ & $(0.21,0.38)$ \\
\hline
\end{tabular}

Figure 7: Triazine- and pyrimidine-based TADF emitters T20-T26.

opposite, prompt and delayed fluorescence components were clearly evidenced for T21-T23. Lifetimes of the delayed components for T21-T23 were 3.5, 13.0 and $10.3 \mu$ s, respectively. Due to the inability of $\mathbf{T 2 0}$ to upconvert its electrons from the triplet to the singlet state, T20-based device could only reach an EQE of 7.2\%. On the opposite, maximum EQEs of 22.0, 19.2 and $18.3 \%$ were obtained for T21-T23-based devices, with CIE coordinates of $(0.148,0.098)$ and $(0.150,0.097)$ for T22- and T23-based devices, respectively. As anticipated, a lower color purity was obtained for T21-based devices resulting from its lower oxidation potential. Recently, a significant enhancement of blue OLED performances was obtained by replacing the triazine acceptor by a 2,4,6-triphenylpyrimidine unit in donoracceptor-based TADF emitters [57]. Considering that the electron acceptor is not symmetrical anymore, positions of the nitrogen atoms will significantly influence the distribution of the electronic cloud and potentially the overlap with the HOMO level. Examination of the electronic properties of $\mathbf{T} 24$ revealed the HOMO and the LUMO levels are located on both the donor and acceptor part, respectively, without any contribution of the phenyl linker. Another situation was found for T25 and T26 since the LUMO predominantly extends on both the acceptor and the phenyl ring which is between the donor and the 4,6diphenylpyrimidine fragment. Due to the smaller overlap of the 
two wavefunctions, a weaker intramolecular charge transfer was attended, enabling to provide an emission in the blue or skyblue region. Optical properties were evaluated in solution confirming this trend, with an emission at 455,476 , and $496 \mathrm{~nm}$ for T24-T26, respectively. Major differences could be found in the contribution of the delayed component in the luminescence decay. Following the trend determined for the intramolecular charge transfer, a regular increase of the prompt component in the overall decay of the three emitters was found, evidencing the up-conversion of the triplet excitons to the singlet ones. The best EQE was obtained for T26-based devices (22.8\%) consistent with the higher delocalization of its electron-donating part, its smaller $\Delta E_{\mathrm{ST}}$ and the higher contribution of the delayed component in the overall luminescence decay. A regular decrease of the EQE was observed for T25-based devices (18.6\%) and T24-based devices (11.8\%), confirming the absence of delayed fluorescence for the last emitter and the reduction of the strength of ICT interactions. Interestingly, the EQE reported for T26-based devices is among the best so far reported for blue OLEDs. Attesting the interest of the community for this new acceptor, other authors developed quasi-simultaneously a struc- ture-performance relationship with T24, T25 and T27-T28 (see Figure 8) [58]. The choice of pyrimidine as the electron acceptor was notably justified by authors due to the easier synthesis of the central core and a versatile peripheral substitution. Additionally, compared to triazine, the LUMO level of pyrimidine is slightly destabilized, facilitating the access to wide bandgap materials. In this work, a more intriguing behaviour was found even for $\mathbf{T 2 4}$ and $\mathbf{T 2 5}$ that have just been discussed above since mechanochromic properties were evidenced for the four emitters. Based on photophysical investigations, the presence of two different packing modes in the solid state were proven. When tested in OLEDs, no clear conclusions could be deduced as results of opposite trends were detected. Thus, if the EQE of T24-based OLEDs was lower than that determined for T27-based OLEDs $(7.2 \%$ and $11.8 \%$, respectively), the opposite trend was found with $\mathbf{T} 25$ and $\mathbf{T} 28$ (12.6\% and 11.8\%, respectively). Only the influence of the symmetrical or the unsymmetrical substitution of the pyrimidine acceptor by the donor was evidenced, following the conclusions of previous authors.<smiles>Cc1ccccc1-c1cc(-c2ccccc2)nc(-c2ccc(N3c4ccccc4C(C)(C)c4ccccc43)cc2)n1</smiles>

T27<smiles>Cc1ccccc1-c1cc(-c2ccc(N3c4ccccc4C(C)(C)c4ccccc43)cc2)nc(-c2ccccc2)n1</smiles>

T28<smiles>Cc1nc(-c2ccc(N3c4ccccc4C(c4ccccc4)(c4ccccc4)c4ccccc43)cc2)cc(-c2ccccc2)c1N1c2ccccc2C(c2ccccc2)(c2ccccc2)c2ccccc21</smiles>

\begin{tabular}{|c|c|c|c|c|}
\hline & T27 & T28 & T29 & T30 \\
\hline reference & {$[58]$} & {$[58]$} & {$[59]$} & {$[59]$} \\
\hline$\Delta E_{\text {ST }}(\mathrm{eV})$ & 0.13 & 0.13 & 0.26 & 0.24 \\
\hline $\begin{array}{c}\text { decay time } \\
\text { delayed component }(\mu \mathrm{s})\end{array}$ & - & - & - & - \\
\hline $\mathrm{EQE}(\%)$ & 11.8 & 11.8 & 19.0 & 20.8 \\
\hline $\mathrm{CIE}(\mathrm{x}, \mathrm{y})$ & $(0.17,0.21)$ & $(0.18,0.30)$ & $(0.16,0.21)$ & $(0.16,0.24)$ \\
\hline
\end{tabular}


Finally, two D-A-D triads comprising the 9,9-diphenyl-9,10dihydroacridine donor were reported in 2016 [59]. Here again, existence of relatively large dihedral angles of $82-87^{\circ}$ between the donor unit and the nearby phenylene linker for T29 and T30 was confirmed by quantum chemical calculations. Resulting from the almost perfect orthogonality, a good confinement of the electronic density of the two orbitals was obtained with a HOMO level predominantly located on the donor and a distribution of the LUMO over the central pyrimidine acceptor core and the adjacent phenylene linkers small $\Delta E_{\mathrm{ST}}$ were determined ( 0.16 and $0.15 \mathrm{eV}$ for $\mathbf{T 2 9}$ and T30, respectively), indicative of reduced electronic correlations between frontier orbitals and accounting for their high performance. Indeed, EQEs of 19.0 and $20.8 \%$, an EL at 468 and $472 \mathrm{~nm}$ were, respectively, determined for T29 and T30. However, the efficiency roll-off was quite severe and this drawback was assigned to the relatively long exciton lifetimes of T29 and T30 in doped films (330 and $210 \mu \mathrm{s}$, respectively). Recently, an original strategy to combine the electron-donating 9,9-dimethyl-10-phenylacridan with the electron-accepting 2,4,6-triphenyl-1,3,5-triazine was reported under the form of random copolymers derived from a polystyrene (T31-T34, see Figure 9) [60]. Contrarily to the classical TADF materials in which the electron donor is connected to the acceptor, interactions between the two moieties occur by mean of a through-space charge transfer (TSCT). Polystyrenes of different compositions T31-T34 were examined, varying by the acceptor content ( 5 or $50 \mathrm{wt} \%$ of acceptor) and the donor units, i.e., 9,9-dimethyl-10-phenylacridan or 9,9bis(3,5-di-tert-butylphenyl)-10-phenylacridan. Precisely, effect of the steric hindrance on TADF properties of the polymers was investigated by introducing a steric hindrance on the electron donor. Use of polystyrene to generate EL materials is counterintuitive due to its inherent insulating character, but EL polymers substituted with iridium complexes have previously been studied in the literature, evidencing the pertinence of the strategy [61].

In this case, charge transport properties are provided by the substituents attached to the polymer chain. As main finding of this work, the detrimental effect of the steric hindrance was demonstrated, no TSCT effects and no TADF features were detected for T33 and T34. Conversely, for the less hindered polymers, a delayed fluorescence could be evidenced for the two polymers T31 and T32, with a ratio for the prompt/delayed component of $13 / 87$, respectively. $\Delta E_{\mathrm{ST}}$ values of 0.019 (T31) and $0.021 \mathrm{eV}$ (T32) were also determined by examining the fluorescence and phosphorescence spectra. Interestingly, the bluest EL emission (472 nm) was obtained for the polymer only containing $5 \mathrm{wt} \%$ of acceptor T31, with an EQE peaking at $12.1 \%$ for these solution-processed OLEDs, what is remarkable. Conversely, a less blue emission was obtained for T32, the emission peaking in the blue-green region $(497 \mathrm{~nm})$.

\section{Phenoxaphosphine oxide and phenoxa- thiin dioxide derivatives}

Recently, phenoxaphosphine oxide and phenoxathiin dioxide have gained interest as electron acceptors since the first report mentioning their use as acceptors was published by Lee et al. in

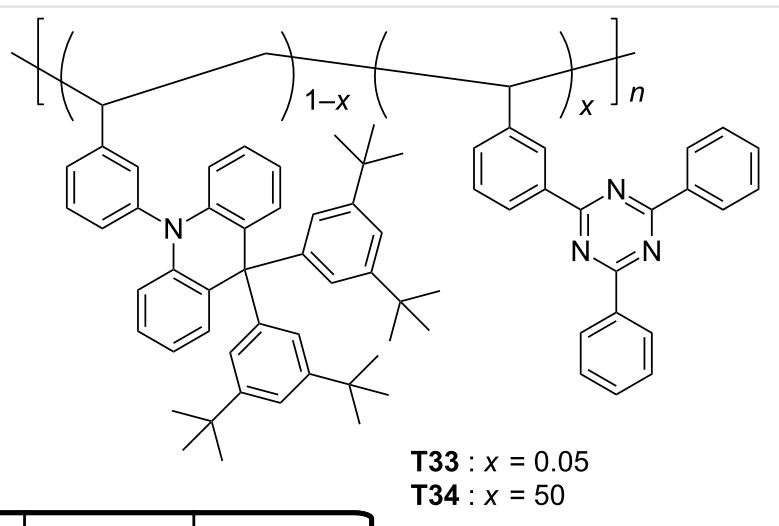

\begin{tabular}{|c|c|c|c|c|}
\hline & T31 & T32 & T33 & T34 \\
\hline reference & {$[60]$} & {$[60]$} & {$[60]$} & {$[60]$} \\
\hline$\Delta E_{\text {ST }}(\mathrm{eV})$ & 0.019 & 0.021 & - & - \\
\hline $\begin{array}{c}\text { decay time } \\
\text { delayed component }(\mu \mathrm{s})\end{array}$ & 1.17 & 1.28 & - & - \\
\hline $\mathrm{EQE}(\%)$ & 3.1 & 12.1 & 0.21 & 0.33 \\
\hline $\mathrm{CIE}(\mathrm{x}, \mathrm{y})$ & $(0.22,0.43)$ & $(0.18,0.27)$ & $(0.23,0.24)$ & $(0.21,0.20)$ \\
\hline
\end{tabular}

Figure 9: Triazine-based TADF polymers T31-T32. 
2016 [62]. Prior to this work, phenoxaphosphine oxide derivatives were mostly studied for the design of flame-retardants [63] or as chiral molecules for fullerene recognition [64-66]. Similarly, the scope of applications of phenoxathiin dioxide ranged from antimicrobial activity [67] to the use as inhibitor for Hepatitis $C$ virus infection [68]. Here, in the context of OLEDs, Lee et al. reported two blue TADF emitters, P1 and P2 (see Figure 10), containing a phenoxaphosphine oxide or a phenoxathiin dioxide acceptor covalently linked to a dimethylacridan donor.

Theoretical calculations predicted the two molecules to adopt in their optimized molecular geometries a highly twisted conformation, what is a requirement for a spatial separation of the HOMO and LUMO energy levels. As attended, the LUMOs of $\mathbf{P 1}$ and $\mathbf{P 2}$ are localized on the acceptor moieties whereas their HOMOs are mostly distributed on the donor. Separation of the frontier orbitals lead to $\Delta E_{\mathrm{ST}}$ values of 0.02 (P1) and $0.10 \mathrm{eV}$ (P2), which are in perfect accordance with the experimental data: $\Delta E_{\mathrm{ST}}=0.03$ and $0.06 \mathrm{eV}$ for $\mathbf{P} \mathbf{1}$ and $\mathbf{P} 2$, respectively. Interestingly, theoretical calculations also showed the higher electron-accepting ability of the phenoxathiin dioxide moiety compared to that of the phenoxaphosphine oxide group owing to the stronger electron-withdrawing properties of the sulfone group, with a theoretical LUMO level at -1.52 and $-1.24 \mathrm{eV}$ for $\mathbf{P 2}$ and P1, respectively. In multilayered devices, remarkable CIE coordinates could be realized with P1- and P2-based OLEDs $((0.15,0.14)$ with $\mathbf{P 1}$ and $(0.16,0.26)$ with P2), combined with high EQEs (12.3\% and $20.5 \%$, respectively). Additionally, for P2-based devices, the efficiency roll-off could be remarkably suppressed and an EQE as high as $13 \%$ could be maintained at the luminance of $1000 \mathrm{~cd} \cdot \mathrm{m}^{-2}$.

\section{CN-Substituted pyridine and pyrimidine derivatives}

In 2015, Liu et al. constructed a novel blue TADF emitter CN-P1 comprising a carbazole donating moiety connected to a pyridine-3,5-dicarbonitrile accepting group (see Figure 11) [69]. The choice of pyridine-3,5-dicarbonitrile as acceptor was notably motivated by the outstanding charge-transport ability and the remarkable electrochemical stability of this group [70,71]. Thus, CN-P1 had a small singlet-triplet splitting $\left(\Delta E_{\mathrm{ST}}=0.04 \mathrm{eV}\right)$, fairish PLQY in doped films (49.7\%), and a delayed decay lifetime of $46.6 \mu \mathrm{s}$, which suggests that it could be a promising candidate as emitter. EL performance of CN-P1 was investigated in OLEDs with different CN-P1 doping concentrations in $m \mathrm{CP}$ as the emitting layers. The highest EQE $(21.2 \%)$ of devices was obtained at $13 \mathrm{wt} \%$ doping conditions. It was found that the maximum EQEs are enlarged along with the increase of doping concentration, which can be mainly attributed to the more efficient exciton utilization with a higher emitter concentration. However, EQEs decreased with the further concentration increase of CN-P1 due to the strong interaction and aggregation between CN-P1 molecules at high doping concentration in the emitting layer. Authors obtained EL spectra red-shifting from sky-blue $\left(\lambda_{\max }=475 \mathrm{~nm}, \mathrm{CIE}=(0.18\right.$, $0.26))$ to greenish-blue $\left(\lambda_{\max }=510 \mathrm{~nm}, \mathrm{CIE}=(0.24,0.40)\right)$ emissions by varying the doping concentration from 5 to $50 \mathrm{wt} \%$. Such red shift is clearly caused by the interaction between CN-P1 molecules at high dopant concentrations. Parallel to this, CN-P1 molecules can also increase the polarity of the EML, thus introducing a solvatochromaticity-like shift comparable to that observed in solutions while varying the solvents polarity. The optimized device exhibited a maximum current efficiency of $47.7 \mathrm{~cd} \cdot \mathrm{A}^{-1}$, and a maximum power efficiency of $42.8 \mathrm{~lm} \cdot \mathrm{W}^{-1}$ without any light outcoupling structures, indicating that nearly $100 \%$ of excitons are harvested for light emission. Such high performance should not only be attributed to the fairish PLQY and the efficient RISC process from $T_{1}$ to $S_{1}$ of CN-P1 emitter, but also owed to the reasonable high $\mathrm{T}_{1}$, good charge mobility, and well-matched PL spectrum of the $\mathrm{mCP}$ host with the CN-P1 absorption spectrum. Still based on pyridine derivatives, Pan et al. prepared a series of twisted $\mathrm{D}-\pi-\mathrm{A}$ type emitters based on the dimethylacridan and different CN-substituted acceptors (pyridine, pyrimidine, and benzene, see Figure 11) [72]. Theoretical calculations showed the different emitters to adopt a nearly orthogonal conformation between the donor and the central aromatic ring, interrupting the<smiles></smiles><smiles>CC1(C)c2ccccc2N(c2ccc3c(c2)Oc2ccccc2S3(=O)=O)c2ccccc21</smiles>

\begin{tabular}{|c|c|c|}
\hline & P1 & P2 \\
\hline reference & {$[62]$} & {$[62]$} \\
\hline$\Delta E_{\mathrm{ST}}(\mathrm{eV})$ & 0.03 & 0.06 \\
\hline $\begin{array}{c}\text { decay time } \\
\text { delayed component }(\mu \mathrm{s})\end{array}$ & 3.8 & 2.7 \\
\hline $\mathrm{EQE}(\%)$ & 12.3 & 20.5 \\
\hline $\mathrm{CIE}(\mathrm{x}, \mathrm{y})$ & $(0.15,0.14)$ & $(0.16,0.26)$ \\
\hline
\end{tabular}




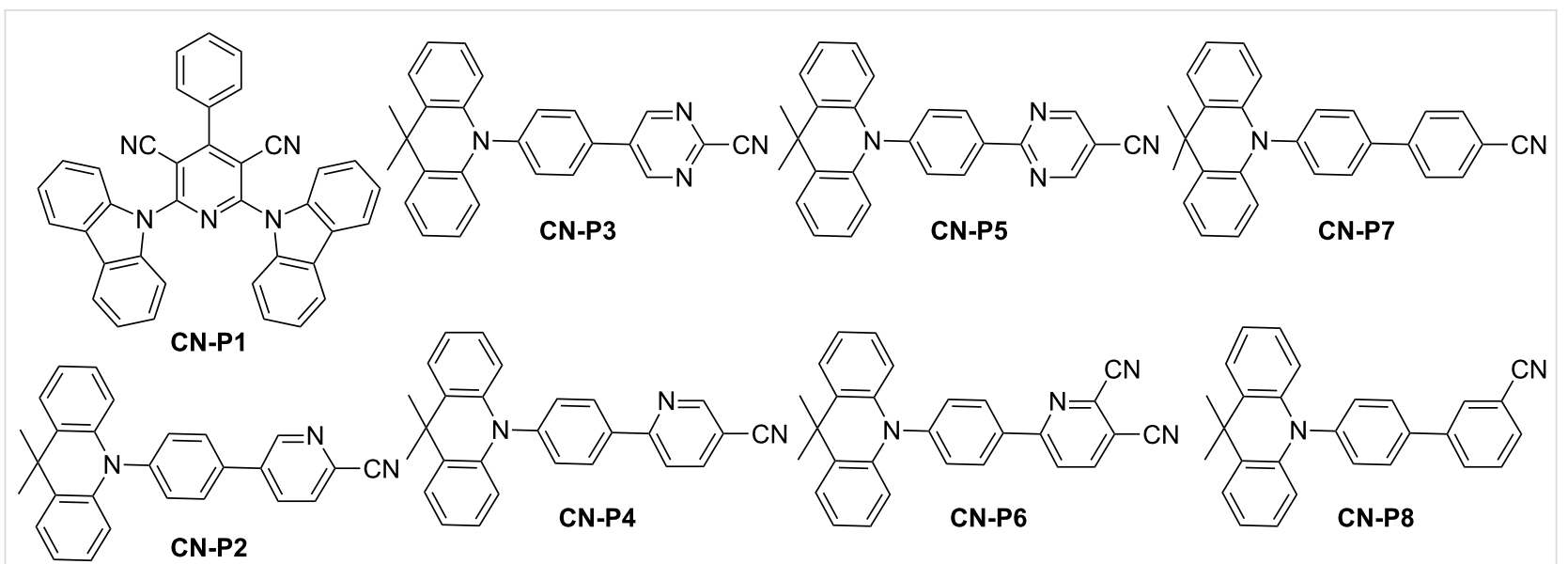

\begin{tabular}{|c|c|c|c|c|c|c|c|c|}
\hline & CN-P1 & CN-P2 & CN-P3 & CN-P4 & CN-P5 & CN-P6 & CN-P7 & CN-P8 \\
\hline reference & {$[69]$} & {$[72]$} & {$[72]$} & {$[72]$} & {$[72]$} & {$[72]$} & {$[72]$} & {$[72]$} \\
\hline$\Delta E_{\text {ST }}(\mathrm{eV})$ & 0.04 & 0.19 & 0.09 & 0.18 & 0.04 & 0.032 & 0.439 & 0.403 \\
\hline $\begin{array}{c}\text { decay time } \\
\text { delayed component }(\mu \mathrm{S})\end{array}$ & 46.6 & 19.3 & 11.6 & 14.5 & 5.2 & 1.9 & 0.03 & 0.01 \\
\hline $\mathrm{EQE}(\%)$ & 21.2 & 23.9 & 31.3 & 23.1 & 30.6 & 29.2 & 5.7 & 1.6 \\
\hline $\mathrm{CIE}(\mathrm{x}, \mathrm{y})$ & $(0.20,0.35)$ & $(0.24,0.49)$ & $(0.32,0.59)$ & $(0.28,0.54)$ & $(0.34,0.57)$ & $(0.43,0.55)$ & $(0.17,0.18)$ & $(0.16,0.06)$ \\
\hline
\end{tabular}

Figure 11: CN-Substituted pyridine and pyrimidine derivatives CN-P1-CN-P8.

$\pi$-conjugation and localizing the HOMO level on the acridan moiety and the LUMO level on the central accepting group. The calculations also predicted a more planar phenyl-pyrimidine/ phenyl-pyridine conformation (i.e., a smaller dihedral angle) in CN-P5/CN-P4 and a more twisted phenyl-pyrimidine/ phenyl-pyridine conformation (i.e., a larger dihedral angle) in CN-P3/CN-P2. All the DFT-optimized data were in perfect accordance with single crystal X-ray diffraction analyses. The results showed that the molecular conformations (twist angles in D-spacer-A diads) could be easily tuned by controlling the orientation of the nitrogen atom(s) in the heteroaromatic rings relative to the donor plane. In fact, two main groups of molecules were identified. Thus, CN-P3, CN-P5 and CN-P6 are characterized by a relatively small $\Delta E_{\mathrm{ST}}$ of $0.032-0.090 \mathrm{eV}$, show the most pronounced contribution of the delayed component in PL with emission quantum yields for the delayed component of luminescence in the $38-44 \%$ range.

These molecules also exhibit high reverse intersystem crossing rates $\left(k_{\mathrm{RISC}}>15 \times 10^{4} \mathrm{~s}^{-1}\right)$. Conversely, CN-P2 and CN-P4 show larger $\Delta E_{\mathrm{ST}}(0.180-0.190 \mathrm{eV})$ than $\mathbf{C N}-\mathbf{P 3}, \mathbf{C N}-\mathbf{P 5}$ and CN-P6 and lower TADF contributions in PL with smaller quantum yields for the delayed component of luminescence $(19-23 \%)$. Smaller RISC were also determined $\left(k_{\mathrm{RISC}}\right.$ of $\left.<8 \times 10^{4} \mathrm{~s}^{-1}\right)$. Finally, TADF contribution on the total luminescence of $\mathbf{C N - P 7}$ and $\mathbf{C N}-\mathbf{P 8}$ was the weakest of the series $(\leq 1 \%)$ as a result of their extremely large $\Delta E_{\mathrm{ST}}(>400 \mathrm{meV})$. Due to the weak contribution of the TADF process, these emitters could be nearly assimilated to conventional fluorescent emitters. All light-emitting materials show lifetimes for the prompt decay component of luminescence in the 6.5-27 ns range whereas the lifetimes for the delayed decay component varied from 1.9 to $19 \mu \mathrm{s}$. All compounds were tested in OLED and all devices exhibited a relatively low turn-on voltage $(\approx 2.5 \mathrm{~V})$ and a low operation voltage $(\approx 3.5-4 \mathrm{~V}$ for a brightness of $\left.100 \mathrm{~cd} \cdot \mathrm{m}^{-2}\right)$. Devices using high-PLQY emitters (PLQY $=90-100 \%)$ exhibited rather high EQEs of up to 23.1-31.3\%, while CN-P7 and CN-P8 having the lower PLQYs gave inferior EQEs of $5.7 \%$ and $1.6 \%$, respectively. Noticeably, emitters showing the most pronounced TADF characteristics (i.e., CN-P6, CN-P3, and CN-P5) furnished the remarkable EL efficiencies of $29.2 \%\left(96.3 \mathrm{~cd} \cdot \mathrm{A}^{-1}, 105.5 \mathrm{~lm} \cdot \mathrm{W}^{-1}\right), 31.3 \%$ $\left(104.5 \mathrm{~cd} \cdot \mathrm{A}^{-1}, 117.2 \mathrm{~lm} \cdot \mathrm{W}^{-1}\right)$, and $30.6 \%\left(103.7 \mathrm{~cd} \cdot \mathrm{A}^{-1}\right.$, $\left.116.3 \mathrm{~lm} \cdot \mathrm{W}^{-1}\right)$, respectively. On the opposite, $\mathbf{C N}-\mathbf{P} 2$ and CN-P4 showing the less pronounced TADF characteristics exhibited similarly high PLQYs (90-92\%) but lower EQEs (23-24\%). Finally, CN-P8, in which the TADF contribution is almost inexistent, furnished the low EQE of 5.7\% (this is also the material exhibiting the lowest PLQY (36\%)), yet such an EQE is still significantly higher than it can be expected from a conventional non-TADF fluorescent emitter of similar PLQY (i.e., EQE can be estimated to be $\approx 2.5-3 \%$ at most), suggesting 
therefore the contribution from the delayed fluorescence in the overall EL process. Although CN-P6, CN-P5, and CN-P3 could reach high maximum EQEs, different efficiency roll-off behaviours could be evidenced with the following order: CN-P6 $<$ CN-P5 $<$ CN-P3. Such a trend for the efficiency roll-off correlate well with the order of their delayed fluorescence lifetimes and their RISC decay rate values in the host film: CN-P6 $<$ CN-P5 $<$ CN-P3 for the delayed fluorescence lifetimes and CN-P6 $>$ CN-P5 $>$ CN-P3 for $k_{\text {RISC. }}$. Such correlation is also observed for CN-P4 and CN-P2 devices. It has been rationalized that a small delayed fluorescence lifetime (and thus effective RISC) is beneficial for faster triplet-to-singlet conversion, for reducing the triplet exciton population at higher brightness/ current, and thus for reducing associated quenching mechanisms (e.g., triplet-triplet annihilation, etc.). This year, Sasabe et al. reported high efficiency blue OLEDs using isonicotinonitrile-based fluorescent emitters comprising 9,10-dihydro-9,9dimethylacridine(s) as donor unit(s) [73]. The chemical structures of the two emitters CN-P9 and CN-P10 is given in Figure 12. While evaluating the optical and photophysical properties of the different materials, all compounds showed reasonably high PLQYs (71-79\%) in the host films, with a sky-blue emission located at 489 and $495 \mathrm{~nm}$ for CN-P9 and CN-P10, respectively. Delayed luminescence lifetimes of $453.7 \mu \mathrm{s}$ and $116.9 \mu \mathrm{s}$, sufficiently small $\Delta E_{\mathrm{ST}}$ of $0.30 \mathrm{eV}$ and $0.28 \mathrm{eV}$ to allow a RISC were also determined for CN-P9 and CN-P10, respectively. Performances of the two sky-blue emitters CN-P9 and CN-P10 were then evaluated in OLEDs. CN-P9-based devices showed a sky-blue emission with CIE chromaticity coordinates of $(0.19,0.36)$, a low turn-on voltage of $3.1 \mathrm{~V}$ and an EQE of $15 \%$. In contrast, CN-P10-based devices showed still a sky-blue emission with CIE coordinates of $(0.22$, 0.45 ), a low turn-on voltage of $2.9 \mathrm{~V}$ but an EQE peaking at $22 \%$, resulting from its smaller $\Delta E_{\mathrm{ST}}$. Considering the EQE values overcoming the 5\% EQE limit for fluorescent materials, contribution of a TADF process in the overall emission of these two emitters was clearly demonstrated.

\section{Phosphine oxide derivatives}

Blue thermally activated delayed fluorescence (TADF) dyes are basically combinations of strong acceptors and weak donors. In their recent work, Duan et al. employed a weak acceptor group to construct a series of weak acceptor-strong donor (WASD)type emitters with a phenoxazine donor [74]. The molecular structures of these fluorescent compounds, namely 4-(10Hphenoxazin-10-yl)phenyl)diphenylphosphine oxide (PO-1), bis(4-(10H-phenoxazin-10-yl)phenyl)phenylphosphine oxide (PO-2), and tris(4-(10H-phenoxazin-10-yl)phosphine oxide (PO-3) are given in Figure 13. Similar absorption spectra were measured in dilute solutions for all compounds, with three characteristic bands detected around 370,320, and $240 \mathrm{~nm}$. The first one was assigned to a $\mathrm{n} \rightarrow \pi *$ transition from the phenoxazine group to the triphenylphosphine oxide group whereas the second and the third peak was attributed to $\pi \rightarrow \pi^{*}$ transitions of the phenoxazine and the phenyl moities, respectively. A relation of proportionality was demonstrated in the intensities of the band, directly related to the number of phenoxazine groups per molecule. Almost identical PL spectra were determined for these molecules, proving the insulating character of the phosphine oxide group and the pertinence of the WASD strategy to preserve the emission color. Consistent with TD-DFT results, $\Delta E_{\mathrm{ST}}$ decreased from 0.26 to 0.19 and finally $0.11 \mathrm{eV}$ for PO-1, PO-2 and PO-3, respectively. Relatively high PLQYs were also determined (45\%, 57\%, and 65\%, for PO-1, PO-2 and PO-3, respectively). PLQY of PO-3-based films were determined as 67\%, higher than the values determined for PO-2- and PO-1doped films. The prompt fluorescence lifetimes of PO-1, PO-2, and PO-3 are gradually increasing from 8 to 13 to $20 \mathrm{~ns}$. In contrast, the respective order of the delayed fluorescent lifetimes is reversed, at 95, 31, and $17 \mu \mathrm{s}$, accompanied by a gradual increase of the quantum yields of $36 \%, 45 \%$, and $51 \%$, respectively. PO-1-based OLED achieved EL emissions with peaks at $448 \mathrm{~nm}$ and CIE coordinates of $(0.16,0.12)$, corresponding to a deep-blue light. PO-2-based devices displayed a blue emission peaking at $460 \mathrm{~nm}$ and CIE coordinates of $(0.16$, $0.20)$.

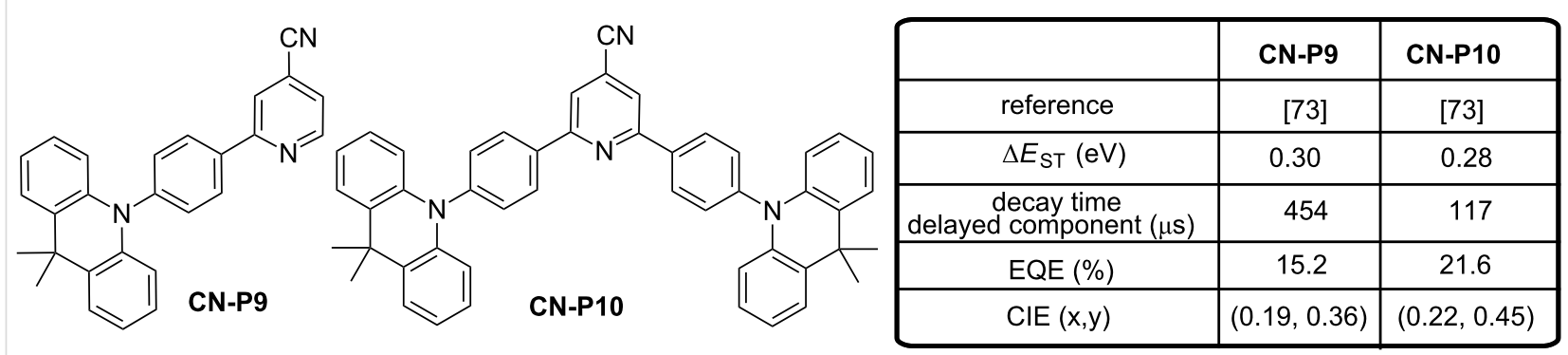




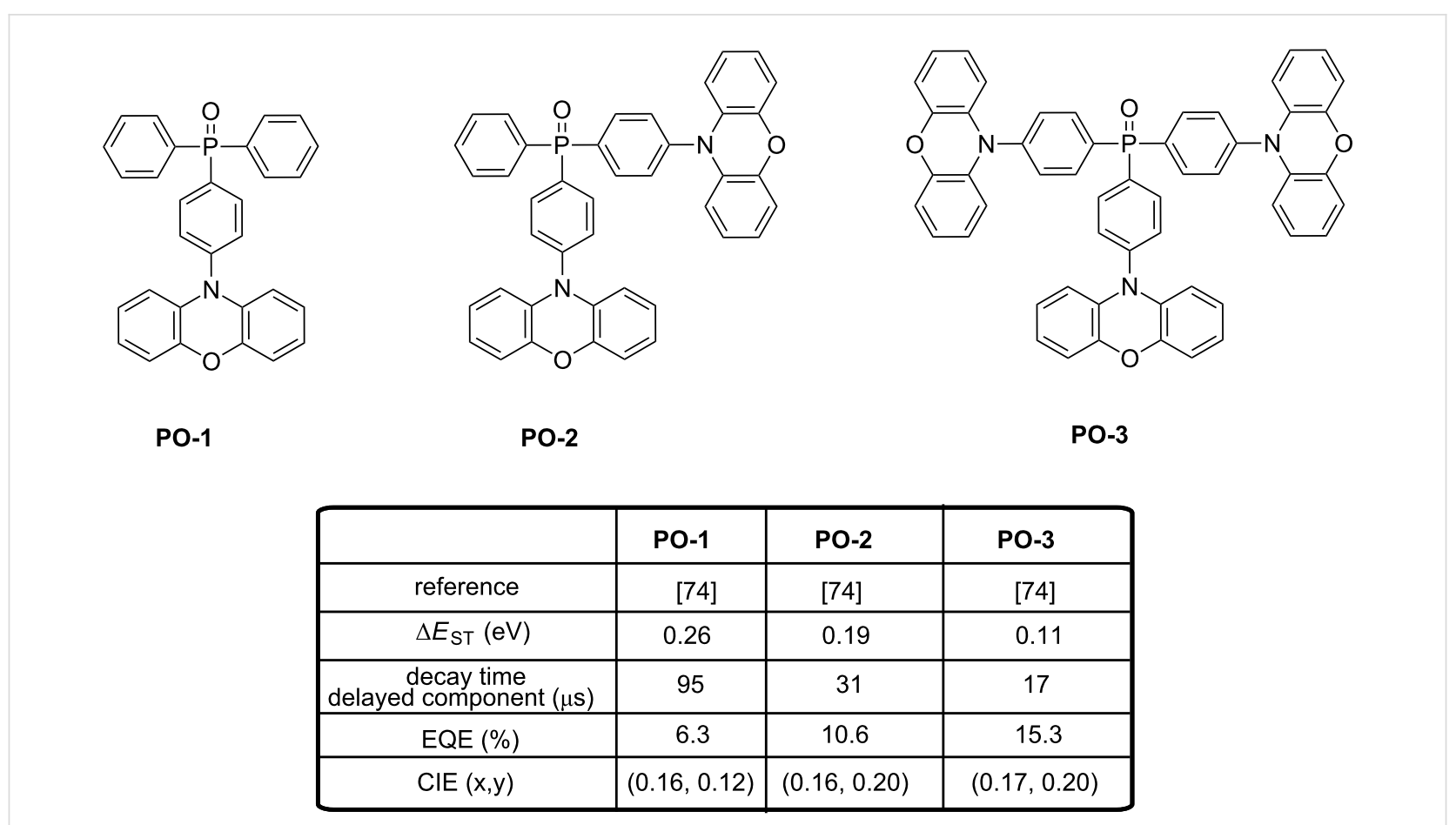

Figure 13: Phosphine oxide-based TADF blue emitters PO-1-PO-3.

OLEDs fabricated with PO-3 produced a pure-blue EL emission peaking at $464 \mathrm{~nm}$, an EQE up to $15.3 \%$, a low efficiency roll-off and CIE coordinates of $(0.17,0.20)$. With aim at simplifying the device fabrication, other authors tried to develop emitters PO-4-PO-9 specifically designed for the fabrication of non-doped OLEDs (see Figure 14) [75]. To reach this goal, the electron-transport diphenylphosphine oxide group was attached to pyrene moieties, providing molecules with good filmforming abilities. High performance of OLEDs was assigned to the judicious combination of an enhanced charge transport ability due to the presence of the diphenylphosphine oxide group, the formation of pyrene excimers in the solid state and the assistance of the TADF property. More precisely, a contribution of a TADF process to the overall EL emission of OLEDs is suggested by the presence within the emissive layer of both pyrene and pyrene excimers, resulting in the presence of closelying singlet and triplet states for the two forms. Besides, if a blue emission of the pyrene excimer assisted by TADF is suggested by the authors, no clear evidence of TADF is provided.

To support the presence of a TADF effect in the devices, the authors tentatively assigned the existence of the delayed component of fluorescence by the presence of close-lying singlet and triplet states in both pyrene derivatives and excimers, favorable to a reverse intersystem crossing giving rise to a delayed fluorescence. Multilayered OLEDs fabricated with PO-4-PO-9 showed interesting efficiencies, with EQEs ranging from 7.2 to $9.1 \%$. The contribution of the diphenylphosphine oxide group to the electron mobilities of these emitters was clearly evidenced by fabricating OLEDs using PO-4-PO-9 as electron-carriers. By comparing with a reference electron-transport material, i.e., $\mathrm{Alq}_{3}$, a two-fold enhancement of EQEs could be determined while using these materials as electron-transport layers, evidencing their higher electron mobilities compared to that of tris(8-hydroxyquinoline)aluminum $\mathrm{Alq}_{3}$. Best OLEDs were obtained with PO-8, EQE peaking at 9.1\%.

\section{Benzonitrile derivatives}

In the search for new acceptors, benzonitrile was identified as a promising candidate capable to contribute to the design of deep blue TADF emitters. Precisely, the cyano moiety is a group limiting the size of electron acceptor moiety by its compacity while remaining one of the strongest electron-accepting groups at disposal for chemists. By combining benzonitrile with two or three carbazole units, and due to the planarity of the two structures (carbazole, benzonitrile), a sufficient steric hindrance could be induced to provide the highly twisted structures BN-1-BN-4 (see Figure 15) [76]. The four carbazolyl benzonitrile derivatives BN-1-BN-4 were easily prepared in a onestep approach through aromatic nucleophilic substitution. Encouraging results were obtained with the four emitters while using high-triplet-energy hosts with favorable carrier injection/ transporting abilities. 


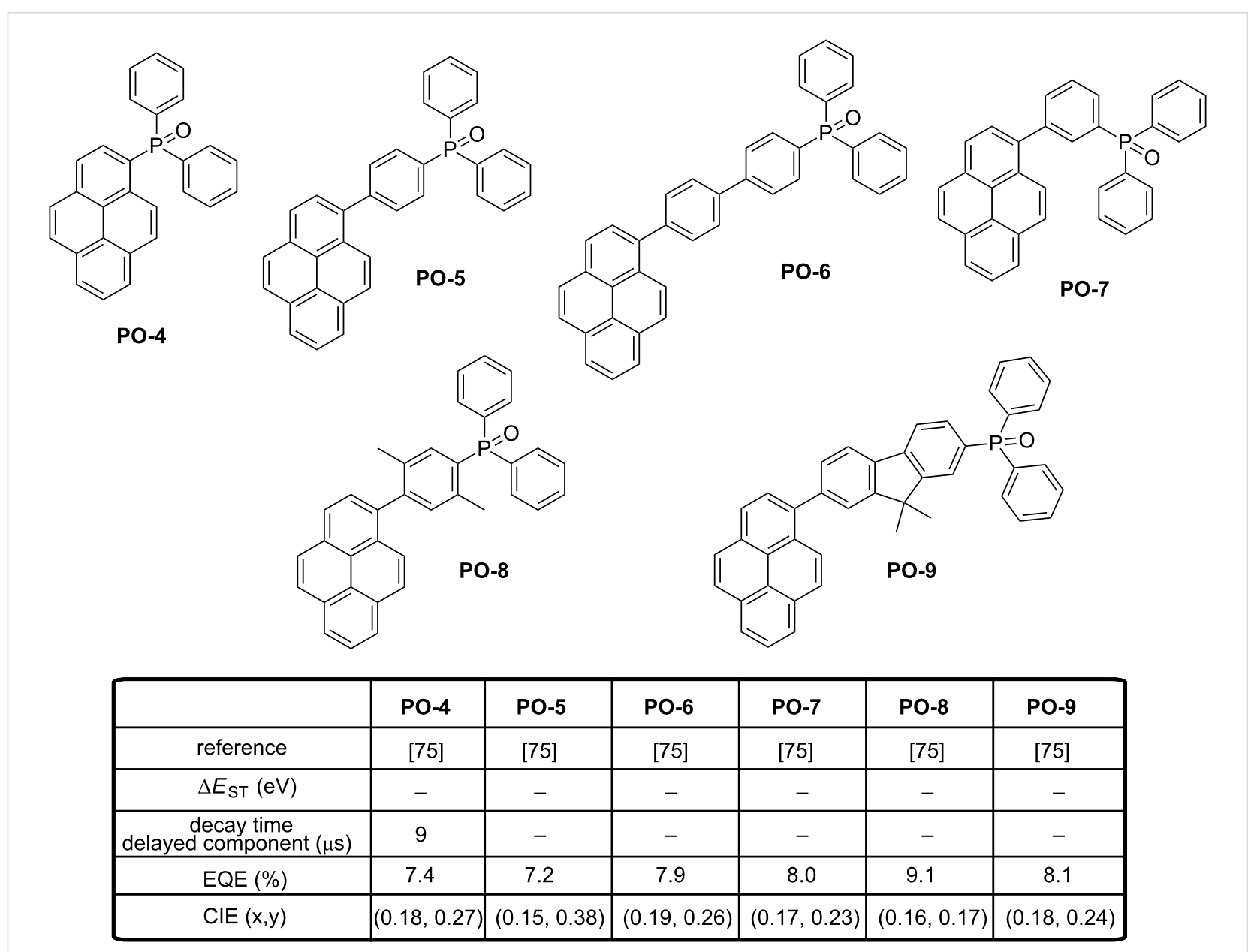

Figure 14: Phosphine oxide-based TADF blue emitters PO-4-PO-9.

The best performance was obtained with BN-2, endowing blueemitting devices with a maximum EQE of $21.5 \%$, which is among the highest values reported for blue TADF devices with an emission peak located at $470 \mathrm{~nm}$. Another possibility could be to increase the number of carbazole units around the benzonitrile moiety. A benzonitrile derivative substituted by five carbazoles (BN-5) was synthesized and characterized by the Adachi team [77]. The OLEDs displayed a light-blue emission and a maximum EQE of $14.8 \%$. Still based on this approach, the group of Hyuk Kwon went even further by introducing a nitrogen atom in the donor, furnishing the carbazole-derived $\alpha$ and $\delta$-carboline where the nitrogen heteroatom is introduced at the $\alpha$ - and $\delta$-position respective to the central nitrogen atom (BN-6 and BN-7, respectively, see Figure 16) [78]. Incorporation of carbolines in these two structures is justified by the fact that this group has recently been identified as an electron-transport material exhibiting a high triplet energy [79-82]. Even if the introduction of heteroatoms in aromatic compounds can increase the molecular relaxation, the bandgap and the triplet energies will simultaneously increase, consequently dimin- ishing $\Delta E_{\mathrm{ST}}$. Effectiveness of the strategy was clearly evidenced by the blue emission produced by OLEDs containing BN-2 as the emitter (CIE coordinates of $(0.19,034)$, EL at $486 \mathrm{~nm}$ ) and the high EQE of $22.5 \%$ attested of the TADF characteristics of the emitter. In contrast, BN-1-based devices demonstrated a low EQE of $4.2 \%$ resulting from its low PLQY ( $37 \%$ contrarily to $93 \%$ for $\mathbf{B N - 2}$ ) and the poor contribution of the delayed component to the overall emission (7\% contrarily to $45 \%$ for BN-2). As a positive point, the EL spectrum of BN-1based devices was blue shifted at $473 \mathrm{~nm}$. Therefore, undeniably, it can be concluded that the effect of the heteroatom position in the carboline donor moiety is essential. Notably, for the two materials, the HOMO and LUMO energy levels of BN-1 and $\mathbf{B N - 2}$ are isolated from each other, but a partial overlap exists in BN-1 due to the weaker donating ability of the $\alpha$-carboline moiety. Jointly, theoretical calculations evidenced a larger bond length change between the ground and excited states for BN-1 $(0.048 \AA$ vs $0.041 \AA$ for BN-2 between the carboline and the phenyl group). As a result of this, the higher molecular relaxation in $\mathbf{B N - 1}$ is expected to favour the non- 


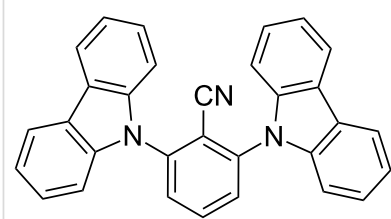

BN-1

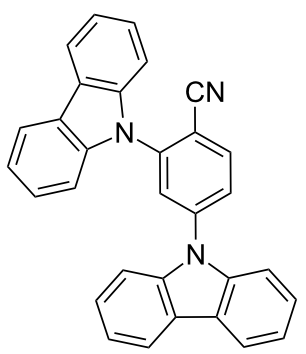

BN-2<smiles>N#Cc1cc(-n2c3ccccc3c3ccccc32)cc(-n2c3ccccc3c3ccccc32)c1</smiles>

BN-3<smiles>Cc1c(-n2c3ccccc3c3ccccc32)cc(-n2c3ccccc3c3ccccc32)cc1-n1c2ccccc2c2ccccc21</smiles>

BN-4

\begin{tabular}{|c|c|c|c|c|c|}
\hline & BN-1 & BN-2 & BN-3 & BN-4 & BN-5 \\
\hline reference & {$[76]$} & {$[76]$} & {$[76]$} & {$[76]$} & {$[77]$} \\
\hline$\Delta E_{\mathrm{ST}}(\mathrm{eV})$ & 0.27 & 0.41 & 0.40 & 0.23 & 0.19 \\
\hline $\begin{array}{c}\text { decayy time } \\
\text { delayed component }(\mu \mathrm{s})\end{array}$ & - & - & - & - & - \\
\hline $\mathrm{EQE}(\%)$ & 13 & 21.5 & 20.1 & 14.8 & 14.8 \\
\hline $\mathrm{CIE}(\mathrm{x}, \mathrm{y})$ & $(0.17,0.29)$ & $(0.16,0.26)$ & $(0.16,0.23)$ & $(0.17,0.28)$ & $(0.15,0.26)$ \\
\hline
\end{tabular}<smiles>[Z4]c1c([CH])c([Z4])c(C#N)c([CH])c1[CH]</smiles><smiles>[C]=[C]c1cccc2c1c1ccccc1n2[Al]</smiles>

BN-5

Figure 15: Benzonitrile-based emitters BN-1-BN-5<smiles></smiles>

BN-6

BN-7

\begin{tabular}{|c|c|c|c|}
\hline & BN-6 & BN-7 & BN-8 \\
\hline reference & {$[78]$} & {$[78]$} & {$[83]$} \\
\hline$\Delta E_{\mathrm{ST}}(\mathrm{eV})$ & 0.28 & 0.13 & 0.02 \\
\hline $\begin{array}{c}\text { decay time } \\
\text { delayed component }(\mu \mathrm{s})\end{array}$ & 57 & 180 & - \\
\hline $\mathrm{EQE}(\%)$ & 4.2 & 22.5 & 15.9 \\
\hline $\mathrm{CIE}(\mathrm{x}, \mathrm{y})$ & $(0.16,0.19)$ & $(0.19,0.34)$ & $(0.16,0.16)$ \\
\hline
\end{tabular}<smiles>CC1(C)c2ccccc2N(c2cccc(N3c4ccccc4C(C(C)(C)C)(C(C)(C)C)c4ccccc43)c2C#N)c2ccccc21</smiles>

BN-8<smiles>CCCC1(CC)c2ccccc2N(c2ccccc2C#N)c2ccccc21</smiles>

BN-9

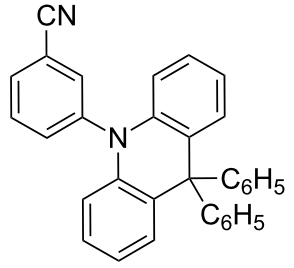

BN-10<smiles>CC(C)(C)C(C)(C)C(C)(C)c1ccccc1N1c2ccccc2N(c2ccc(C#N)cc2)c2ccccc21</smiles>

$\mathrm{BN}-11$

Figure 16: Benzonitrile-based emitters BN-6-BN-11

radiative processes, adversely affecting the EL performance. Another study revealed the importance of the donor moiety position compared to benzonitrile for high EL efficiency. In an effort to maximize the TADF process, Adachi developed a series of four highly twisted molecules BN-8-BN11 consisting of the combination of 9,9-diphenylacridane donor unit(s) connected to a benzonitrile central core (see Figure 16) [83]. As first conclusions extracted from the theoretical calculations, the predicted $\Delta E_{\mathrm{ST}}$ values were similar for all molecules $(0.03 \mathrm{eV})$, suggesting that the substitution position has no effect on the up-conversion properties. Parallel to this, examination of the PL spectra of BN-8-BN-11 showed the PL maximum to be located 
at 454 and $441 \mathrm{~nm}$ for $\mathbf{B N - 8}$ and BN-9, respectively, whereas the emission was detected at 433 and $428 \mathrm{~nm}$ for the metasubstituted $\mathbf{B N - 1 0}$ and para-substituted BN-11, respectively.

It was thus concluded that the $\pi$-conjugation was maximized upon ortho-substitution and the introduction of two donor units on BN-8 optimized the delayed emission intensity so that $\mathbf{B N - 8}$ was the only one to be tested in devices. OLEDs fabricated using BN-8 as an emitter showed a blue emission at $463 \mathrm{~nm}$ (with CIE coordinates of $(0.16,0.16)$ ) that coincides the PL emission maximum together with the high EQE of $15.9 \%$. However, examination of the chemical stability of an encapsulated film of $\mathbf{B N - 8}$ evidenced the emission intensity of the film to decrease in less than $5 \mathrm{~min}$ upon photoexcitation. Theoretical calculations pointed out the ortho-substitution to enhance the TADF efficiency because of the optimized steric hindrance but also to decrease the bond dissociation energy as a value of only $0.94 \mathrm{eV}$ for the $\mathrm{C}-\mathrm{N}$ bond was determined, much lower than the singlet and triplet energies of the molecules $(2.75 \mathrm{eV}$ and $2.73 \mathrm{eV}$, respectively).

\section{Benzoylpyridine and}

\section{di(pyridinyl)methanone-carbazole derivatives} Emitters displaying efficient RISC and high PLQY are promising candidates for OLEDs and molecules comprising phenyl(pyridin-4-yl)methanone as the acceptor moiety are one of those. As first approach, the two carbazole donors were intro- duced at the ortho- and meta-positions of the phenyl ring of the acceptor (see Figure 17, BP-1 and BP-2) [84]. Very small $\Delta E_{\mathrm{ST}}$ of 0.03 and $0.04 \mathrm{eV}$ and very high PL efficiencies of 88.0 and 91.4\% were, respectively, determined for BP-1 and BP-2 in codoped films. These values are higher than that determined in solution for the two molecules (4.4 to $14.2 \%$ depending of the solvent for BP-1, 2.8 to $34.0 \%$ depending of the solvent for BP-2), demonstrating the suppression of the collisional and the intramolecular rotational quenching in thin films. However, the substitution pattern of carbazole drastically modified the emission wavelengths and a red-shift of approximately $20 \mathrm{~nm}$ was observed upon introduction of tert-butyl substituents on BP-2. Conversely, a higher electrochemical stability was determined for BP-2 upon repeating CV scans, the two reactive $\mathrm{C}_{3}$ and $\mathrm{C}_{6}$ sites in para-position relative to the nitrogen atom of the carbazole being blocked by the tert-butyl groups. In multilayered devices, the bluer emitter BP-1 provided efficiencies comparable to those obtained with iridium-based phosphorescent OLEDs at similar EL wavelength $[85,86]$. Notably, skyblue BP-1-based OLEDs reached a maximum efficiency of $24 \%$ for the light peaking at $488 \mathrm{~nm}$. The same year (2016), the same authors changed their strategy and combined all electron donors together, replacing the former $\mathrm{D}-\mathrm{A}-\mathrm{D}$ triads by $\mathrm{D}-\mathrm{A}$ diads [87]. To tune the electron donating ability, carbazoles were introduced at the outer position of a carbazole unit, at the 3 and 3,6-conjugated positions of the first carbazole, resulting in donors composed in total of one to three carbazole groups.<smiles>[R]c1ccc2c(c1)c1cc([R])ccc1n2-c1ccc(-n2c3ccc([R])cc3c3cc([R])ccc32)c(C(=O)c2ccncc2)c1</smiles><smiles>[R]c1ccc2c(c1)c1cc([R])ccc1n2-c1ccc(C(=O)c2ccncc2)cc1</smiles>

BP-3: $\mathrm{R}=\mathrm{H}$ BP-6: $\mathrm{R}=t-\mathrm{Bu}$<smiles>O=C(c1ccncc1)c1ccc(-n2c3ccccc3c3cc(-n4c5ccccc5c5ccccc54)ccc32)cc1</smiles>

\begin{tabular}{|c|c|}
\hline BP-6 \\
\hline$[87]$ \\
\hline 0.13 \\
\hline- \\
\hline 32$)$ & $(0.17,0.27)$ \\
\hline
\end{tabular}

\begin{tabular}{|c|c|c|c|c|c|c|}
\hline & BP-1 & BP-2 & BP-3 & BP-4 & BP-5 & BP-6 \\
\hline reference & {$[83]$} & {$[83]$} & {$[87]$} & {$[87]$} & {$[87]$} & {$[87]$} \\
\hline$\Delta E_{\text {ST }}(\mathrm{eV})$ & 0.03 & 0.04 & 0.29 & 0.07 & 0.05 & 0.13 \\
\hline $\begin{array}{c}\text { decay time } \\
\text { delayed component }(\mu \mathrm{s})\end{array}$ & 0.6 & 1 & - & - & 0.65 & - \\
\hline $\mathrm{EQE}(\%)$ & 24.0 & 27.2 & 4.2 & 11.0 & 23.9 & 9.4 \\
\hline $\mathrm{CIE}(\mathrm{x}, \mathrm{y})$ & $(0.17,0.36)$ & $(0.30,0.64)$ & $(0.16,0.13)$ & $(0.18,0.28)$ & $(0.19,0.32)$ & $(0.17,0.27)$ \\
\hline
\end{tabular}<smiles>CCC(C)n1c2ccc(-n3c4ccccc4c4ccccc43)cc2c2cc(-n3c4ccccc4c4ccccc43)ccc21</smiles>

Figure 17: Benzoylpyridine-carbazole hybrid emitters BP-1-BP-6. 
Comparison established with this series of emitters evidenced a clear decrease of $\Delta E_{\mathrm{ST}}$ upon expending the size of the donating part and the number of carbazole units per donor. Thus, $\Delta E_{\mathrm{ST}}$ decreased from $0.29 \mathrm{eV}$ for $\mathbf{B P}-\mathbf{3}$ to $0.07 \mathrm{eV}$ for BP-4 and $0.05 \mathrm{eV}$ for BP-5, consistent with a higher spatial HOMO and LUMO separation and a more extended molecular HOMO orbital distribution.

Unfortunately, despites these favorable features, a significant red-shift of the emission was evidenced for BP-4 and BP-5 as a result of a dual emission, one corresponding to a carbazolecentered $\pi-\pi^{*}$ transition at high energy and an additional but unexpected intramolecular charge transfer only observed for BP-4 and BP-5 at lower energy. A clear shift of the emission maximum was notably evidenced in toluene, the maximum emission wavelength shifting from $440 \mathrm{~nm}$ for BP-3 to $480 \mathrm{~nm}$ for BP-4 and $482 \mathrm{~nm}$ for BP-5. Therefore, only blue devices could be fabricated with the mono-substituted emitter BP-3 and a comparison was established with BP-6 differing from BP-3 by the substitution pattern of the unique carbazole. Once again, a red-shift of the emission was observed upon incorporation of tert-butyl groups on carbazole, the emission in toluene being detected at $467 \mathrm{~nm}$. Evaluation of the potential of BP-3 and
BP-6 as new developed emitters for OLEDs confirmed the trend observed by PL and BP-3 furnished a more blue OLED than BP-6, with an external efficiency peaking at 9.4\%. By optimizing the device structure [88], the same authors could drastically increase the EQE of BP-3-based devices up to $18.4 \%$, even if a non-negligible red-shift of the emission wavelength could be observed: $474 \mathrm{~nm},(0.16,0.25)$ for this study [88] contrarily to the previous emission detected at $452 \mathrm{~nm},(0.13$, 0.16) [87]. Inspired by the structure of BP-2, the same authors developed a series of three fluorescent molecules by varying the position of the nitrogen atom of the pyridine moieties BP-7-BP-9 [89]. All molecules are characterized by high PLQYs in thin films, ranging from 92 to $97 \%$, and small $\Delta E_{\mathrm{ST}}$ varying from $0.01 \mathrm{eV}$ for $\mathbf{B P - 7}$ to $0.05 \mathrm{eV}$ for $\mathbf{B P - 8}$ and 0.02 for BP-9. Despites these appealing photophysical characteristics, positions of EL peaks appeared at 490, 476 and $490 \mathrm{~nm}$ for BP-7-BP-9-based devices, respectively, therefore in the bluegreen region. While comparing with the standard triplet emitter Firpic, a clear enhancement of the EL performance was observed, EQE of Firpic-based OLEDs peaking at $18.7 \%$ whereas EQEs of 2.1, 24.6 and $28.0 \%$ could be, respectively, realized with the three TADF emitters BP-7-BP-9 (see Figure 18). Here again, the ability of TADF emitters to outperform the standard<smiles>CC(C)(C)c1ccc2c(c1)c1cc(C(C)(C)C)ccc1n2-c1cc(C(=O)c2ccncc2)cc(-n2c3ccc(C(C)(C)C)cc3c3cc(C(C)(C)C)ccc32)c1</smiles>

BP-7<smiles>CC(C)(C)c1ccc2c(c1)c1cc(C(C)(C)C)ccc1n2-c1cc(C(=O)c2cccnc2)cc(-n2c3ccc(C(C)(C)C)cc3c3cc(C(C)(C)C)ccc32)c1</smiles>

BP-8<smiles>CC(C)(C)c1ccc2c(c1)c1cc(C(C)(C)C)ccc1n2-c1cc(C(=O)c2ccccn2)cc(-n2c3ccc(C(C)(C)C)cc3c3cc(C(C)(C)C)ccc32)c1</smiles>

BP-9

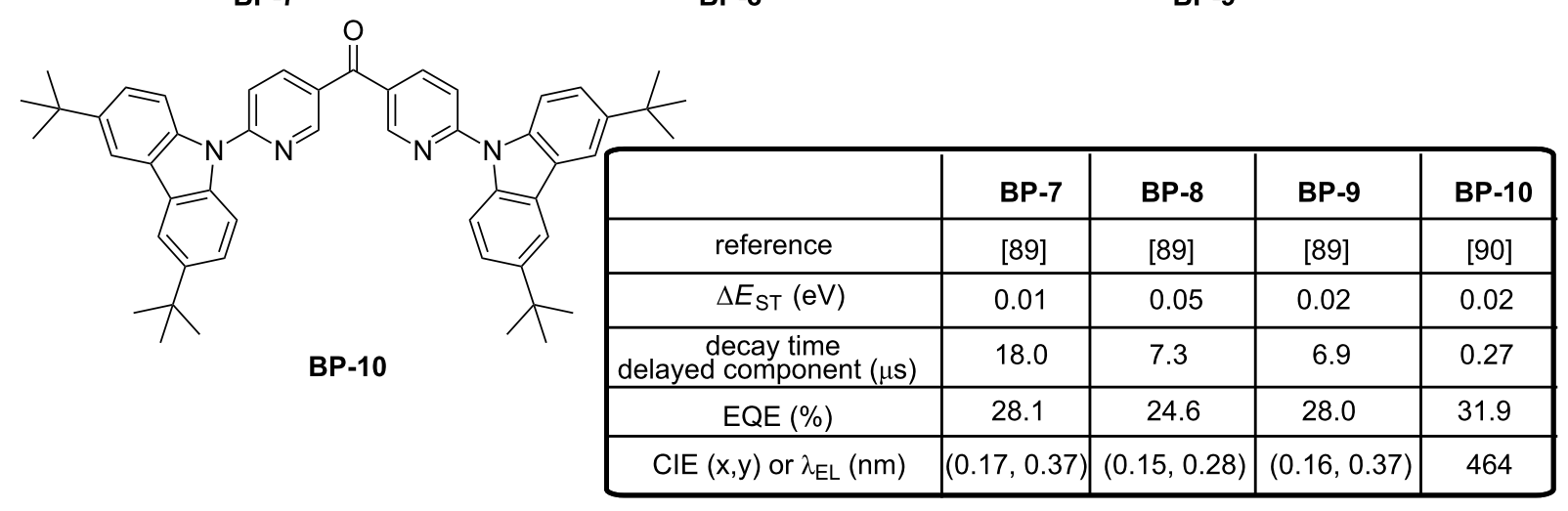

Figure 18: Benzoylpyridine-carbazole hybrid emitters BP-7-BP-10. 
phosphorescent emitters was demonstrated. Finally, the key to produce a pure blue emission with pyridine-based emitters seems to have been found with the di(pyridinyl)methanone electron-accepting core that could furnish a superior pure blue emission compared to emitters based on the benzoylpyridine core [90]. By introducing two pyridines in bis(6-(3,6-di-tert-butyl9H-carbazol-9-yl)pyridin-3-yl)methanone (BP-10), a nearly planar molecule could be obtained, favouring the horizontal molecular orientation of the molecule within the co-doped emissive layer. By this specific arrangement in the EML, a perfect stacking of the molecules parallel to the substrate was determined, providing an isotropic orientation of the transition dipole moment. Finally, OLEDs fabricated with BP-10 with a classical device structure furnished a record-breaking EQE of almost $32 \%$ with a relatively low dopant concentration (7 wt \%) and an emission located at $464 \mathrm{~nm}$.

\section{Triazole derivatives}

3,4,5-Triphenyl-4H-1,2,4-triazole is a good electron acceptor but also a remarkable electron-transport material used for the design of numerous OLED materials ranging from charge-transport materials to light-emitting materials [91-93]. Logically, combination of 3,4,5-triphenyl-4H-1,2,4-triazole with the electron-donor phenoxazine could provide emitters with TADF properties if conveniently associated and such assemblies were reported for the first time in 2013 (see Figure 19) [94]. Comparison of the diad Trz-1 and the triad Trz-2 evidenced in the absence of oxygen the triad Trz-2 to be more luminescent than the diad Trz-1 (29.8 and 43.1\% for Trz-1 and Trz-2, respectively). This trend was confirmed with the design of another series of diad/triads comprising an oxadiazole as the central electron acceptor. This characteristic is opposite to the trend classically reported in the literature where the molecules with a large oscillator strength show a high PLQY [95]. In the present case, the opposite situation was found as the more luminescent materials Trz-2 showed the smaller oscillator strength, evidencing that the order of the PLQYs was not only controlled by the oscillator strength, but also by a competition with vibronic couplings responsible from nonradiative deactivation pathways. The fabrication of OLEDs with the most luminescent Trz-2 furnished sky-blue OLEDs reflecting its PL spectrum in thin doped films $\left(\lambda_{\mathrm{EL}}=456 \mathrm{~nm}, \mathrm{EQE}=6.4 \%\right)$.

\section{Triphenylamine derivatives}

Triphenylamine is a remarkable electron-donating group that found applications in numerous research fields ranging from OLEDs to organic photovoltaics [96]. In the context of TADF blue emitters, an original strategy to tune the emission wavelength consisted in solely changing the sulfur atom valence state of the thioxanthone core, enabling the emission color to shift from blue to yellow [97]. Even if several connecting modes for the triphenylamine moieties onto the thioxanthone core was envisioned, a blue PL was only detected for TPA-1 by introducing the two triphenylamine groups at the para-positions of the carbonyl group in 9H-thioxanthen-9-one (see Figure 20). Because of this specific substitution, a minimal HOMO/LUMO overlap was evidenced by theoretical calculations. Despites the symmetrical substitution of TPA-1 and the reduction of the oscillator strength in the triad, the PLQY remained high, reaching 35\% regardless doped or neat films under air conditions. In a standard device stacking, highly efficient emission could be realized as a maximum EQE value of $23.7 \%$ was obtained for OLEDs comprising an emissive layer with a doping concentration of $1 \mathrm{wt} \%$ and CIE coordinates of $(0.139,0.280)$.

In 2017, more blue OLEDs were obtained by using malononitrile as the electron acceptor [98]. The molecular orientation of the emitting material is essential to optimize the EL characteristics and an increase of the external efficiency by up to $46 \%$ can be achieved if the molecules are perfectly aligned horizontally by giving rise to light-outcoupling effects [99-101]. In this work, TPA-2 and TPA-3 share a similar $\Delta E_{\mathrm{ST}}$ and similar PL characteristics but major differences were found upon fabrication of OLEDs with these two materials. Notably, the current efficiency of OLEDs elaborated with TPA-3 as dopant was approximately 9 times higher than that determined for TPA-2based OLEDs (12.6 and $1.4 \mathrm{~cd} / \mathrm{A}$, respectively). To explain these differences, the perfect horizontal orientation of TPA-3 in

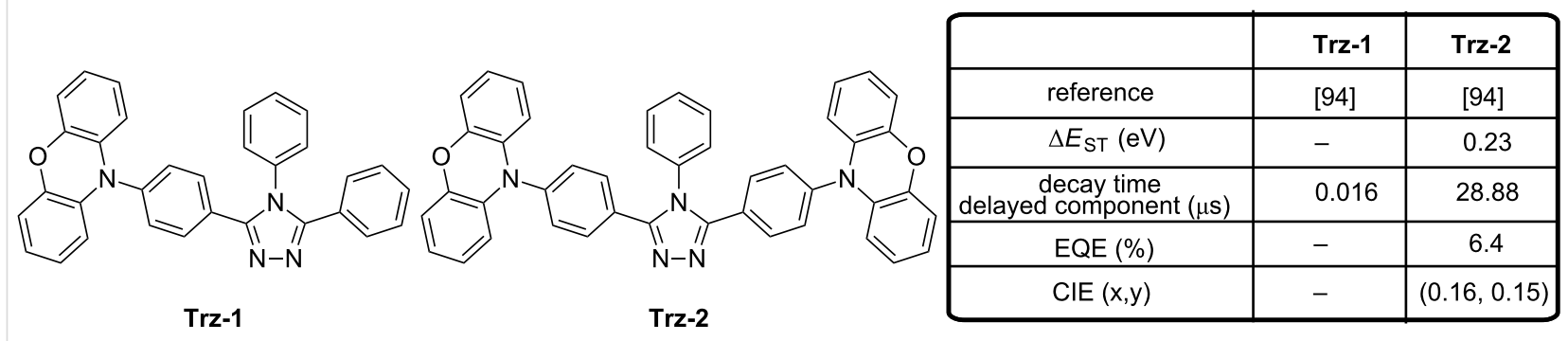

Figure 19: Triazole-based emitters Trz-1 and Trz-2. 


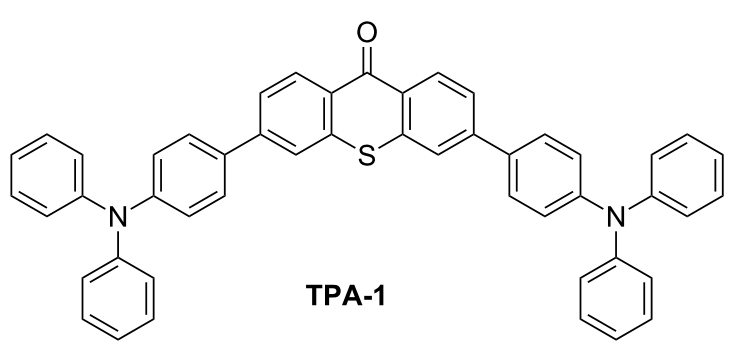<smiles>N#CC(C#N)=C(c1ccc(N(c2ccccc2)c2ccccc2)cc1)c1ccc(N(c2ccccc2)c2ccccc2)cc1</smiles>

\begin{tabular}{|c|c|c|c|}
\hline & TPA-1 & TPA-2 & TPA-3 \\
\hline reference & {$[97]$} & {$[98]$} & {$[98]$} \\
\hline$\Delta E_{\mathrm{ST}}(\mathrm{eV})$ & 0.38 & 0.114 & 0.098 \\
\hline $\begin{array}{c}\text { decay time } \\
\text { delayed component }(\mu \mathrm{s})\end{array}$ & - & 10 & 10 \\
\hline $\mathrm{EQE}(\%)$ or $\mathrm{CE}(\mathrm{cd} / \mathrm{A})$ & $23.7 \%$ & $1.38 \mathrm{~cd} / \mathrm{A}$ & $12.62 \mathrm{~cd} / \mathrm{A}$ \\
\hline $\mathrm{CIE}(\mathrm{x}, \mathrm{y})$ & $(0.14,0.28)$ & $(0.17,0.17)$ & $(0.16,0.20)$ \\
\hline
\end{tabular}

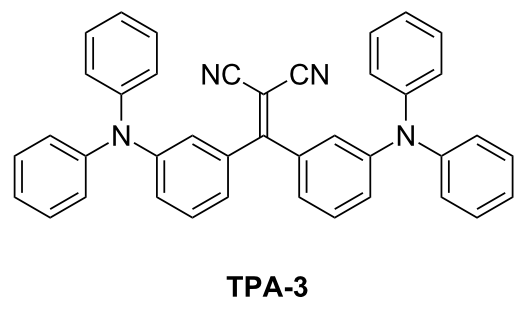

\section{CE: current efficiency}

Figure 20: Triarylamine-based emitters TPA-1-TPA-3.

doped films contrarily to the weak crystallinity and random orientation of TPA-2 resulted in an improvement of the light extraction for TPA-3-based devices, justifying the enhanced performance.

\section{Conclusion}

To conclude, a wide range of strategies are currently developed to produce a blue TADF emission. Among the different findings that can constitute a guideline for the molecular design for blue TADF emitters, it can be cited: 1) The interruption of the $\pi$-conjugation by introducing an orthogonality between the donor and the acceptor to minimize the coupling between the two parts, 2) the fact to maintain the donor close to the acceptor to prevent a complete isolation of the donor and the acceptor, 3 ) the extension of the $\pi$-conjugated system of the donor and/or acceptor to maximize the oscillator strength and thus to increase the PLQY, 4) a minimization of $\Delta E_{\mathrm{ST}}$ to optimize the rate constant of the reverse intersystem crossing, 5) the elaboration of light emitting materials with lifetimes of the delayed component of luminescence as short as possible to address the excited states annihilation issue, 6) a careful selection of the connectivity introduced between the electron donor/acceptor moieties as exemplified by the difference of the EL performance for materials differing by the substitution (ortho-, meta- and para-position of aromatic rings). The different results and observations reported in this review have clearly evidenced that a great deal of efforts has still to be done to produce a deep blue EL, as evidenced in Figure 21. At present, the bluest emitters reported in the literature, i.e., emitters with CIE $x$-coordinate below 0.16 and CIE $y$-coordinate below 0.10 only four are known: D3
$(0.15,0.07)$ [29], reported in 2012, T22 and T23 $(0.15,0.10)$ [45], reported in 2017, and finally CN-P8 $(0.16,0.06)$ [59], reported in 2016. D3, T22 and T23 are all based on carbazole, but carbazole is certainly not the best candidate for the design of highly stable deep blue emitter because of the photo-assisted electrochemical degradation processes it can initiate.

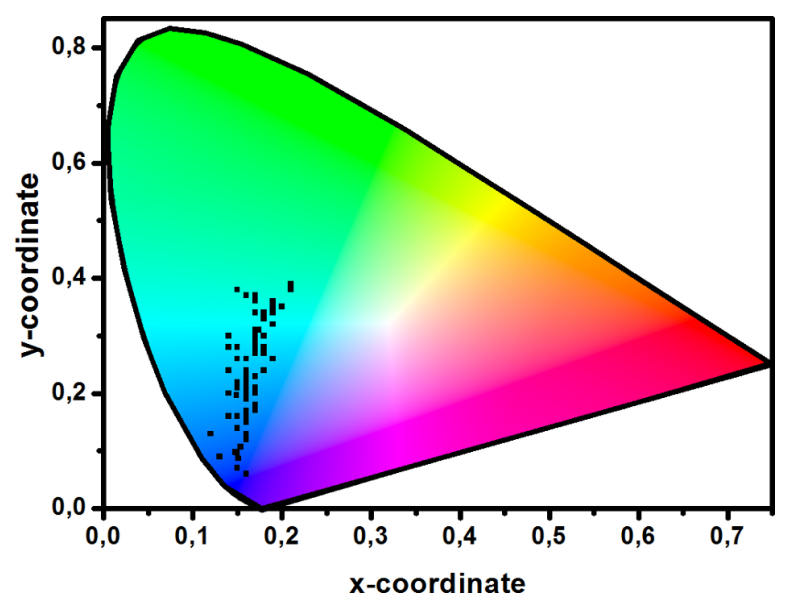

Figure 21: Distribution of the CIE coordinates of ca. 90 blue TADF emitters listed in this review.

Since 2016, a great deal of efforts has been done to investigate new structures issued from communities other than Organic Electronics and electron donors such as phenoxaphosphine oxide or phenoxathiin dioxide and electron acceptors such as $\alpha$ and $\delta$-carbolines that have historically been used for the design 
of biologically active molecules are now commonly used during the elaboration of light emitting materials. Blue and stable emitters that will be developed in the future will certainly comprise such unprecedented moieties. Recently, another aspect of crucial importance to increase the EL performance concerns the molecular alignment of the emitter molecules in OLEDs as this can have an important effect on the outcoupling efficiency; this point warrants more systematic investigations in the future.

\section{ORCID ${ }^{\circledR}$ iDs}

Thanh-Tuân Bui - https://orcid.org/0000-0002-5367-2738

Frédéric Dumur - https://orcid.org/0000-0003-4872-094X

\section{References}

1. Tang, C. W.; VanSlyke, S. A. Appl. Phys. Lett. 1987, 51, 913-915. doi:10.1063/1.98799

2. Gaspar, D. J.; Polikarpov, E. OLED Fundamentals: Materials, Devices, and Processing of Organic Light-Emitting Diodes; CRC Press/Taylor and Francis Group: Boca Raton, FL, United States (US), 2015.

3. Fröbel, M.; Schwab, T.; Kliem, M.; Hofmann, S.; Leo, K.; Gather, M. C. Light: Sci. Appl. 2015, 4, e247. doi:10.1038/lsa.2015.20

4. Baldo, M. A.; O’Brien, D. F.; Thompson, M. E.; Forrest, S. R. Phys. Rev. B: Condens. Matter Mater. Phys. 1999, 60, 14422-14428. doi:10.1103/PhysRevB.60.14422

5. Baldo, M. A.; O’Brien, D. F.; You, Y.; Shoustikov, A.; Sibley, S.; Thompson, M. E.; Forrest, S. R. Nature 1998, 395, 151-154. doi:10.1038/25954

6. Dumur, F.; Bertin, D.; Gigmes, D. Int. J. Nanotechnol. 2012, 9, 377-395. doi:10.1504/IJNT.2012.045343

7. Dumur, F. Synth. Met. 2014, 195, 241-251. doi:10.1016/j.synthmet.2014.06.018

8. Dumur, F. Org. Electron. 2015, 21, 27-39. doi:10.1016/j.orgel.2015.02.026

9. Uoyama, H.; Goushi, K.; Shizu, K.; Nomura, H.; Adachi, C. Nature 2012, 492, 234-238. doi:10.1038/nature11687

10. Tao, Y.; Yang, C.; Qin, J. Chem. Soc. Rev. 2011, 40, 2943-2970. doi:10.1039/c0cs00160k

11. Godumala, M.; Choi, S.; Cho, M. J.; Choi, D. H. J. Mater. Chem. C 2016, 4, 11355-11381. doi:10.1039/C6TC04377A

12. Wong, M. Y.; Zysman-Colman, E. Adv. Mater. 2017, 29, 1605444. doi:10.1002/adma.201605444

13. Li, Y.; Liu, J.-Y.; Zhao, Y.-D.; Cao, Y.-C. Mater. Today 2017, 20 , 258-266. doi:10.1016/j.mattod.2016.12.003

14. Yang, Z.; Mao, Z.; Xie, Z.; Zhang, Y.; Liu, S.; Zhao, J.; Xu, J.; Chi, Z.; Aldred, M. P. Chem. Soc. Rev. 2017, 46, 915-1016. doi:10.1039/C6CS00368K

15. Im, Y.; Kim, M.; Cho, Y. J.; Seo, J.-A.; Yook, K. S.; Lee, J. Y. Chem. Mater. 2017, 29, 1946-1963. doi:10.1021/acs.chemmater.6b05324

16. Im, Y.; Byun, S. Y.; Kim, J. H.; Lee, D. R.; Oh, C. S.; Yook, K. S.; Lee, J. Y. Adv. Funct. Mater. 2017, 27, 1603007. doi:10.1002/adfm.201603007

17. Zhu, M.; Yang, C. Chem. Soc. Rev. 2013, 42, 4963-4976. doi:10.1039/c3cs35440g

18. Fu, H.; Cheng, Y.-M.; Chou, P.-T.; Chi, Y. Mater. Today 2011, 14, 472-479. doi:10.1016/S1369-7021(11)70211-5
19. Chen, W.-C.; Lee, C.-S.; Tong, Q.-X. J. Mater. Chem. C 2015, 3, 10957-10963. doi:10.1039/C5TC02420J

20. Winter, S.; Reineke, S.; Walzer, K.; Leo, K. Proc. SPIE 2008, 6999, 69992N. doi:10.1117/12.782784

21. Scholz, S.; Kondakov, D.; Lüssem, B.; Leo, K. Chem. Rev. 2015, 115, 8449-8503. doi:10.1021/cr400704v

22. Endo, A.; Sato, K.; Yoshimura, K.; Kai, T.; Kawada, A.; Miyazaki, H.; Adachi, C. Appl. Phys. Lett. 2011, 98, 083302. doi:10.1063/1.3558906

23. Busmann, H.-G.; Staerk, H.; Weller, A. J. Chem. Phys. 1989, 91 , 4098-4105. doi:10.1063/1.457624

24. Berberan-Santos, M. N.; Garcia, J. M. M. J. Am. Chem. Soc. 1996, 118, 9391-9394. doi:10.1021/ja961782s

25. Turro, N. J.; Ramamurthy, V.; Scaiano, J. C. Principles of Molecular Photochemistry: An Introduction; Chapter 2; University Science Books: Sausalito, 2008.

26. Etherington, M. K.; Franchello, F.; Gibson, J.; Northey, T.; Santos, J.; Ward, J. S.; Higginbotham, H. F.; Data, P.; Kurowska, A.; Lays Dos Santos, P.; Graves, D. R.; Batsanov, A. S.; Dias, F. B.; Bryce, M. R.; Penfold, T. J.; Monkman, A. P. Nat. Commun. 2017, 8, No. 14987. doi:10.1038/ncomms14987

27. Samanta, P. K.; Kim, D.; Coropceanu, V.; Brédas, J.-L. J. Am. Chem. Soc. 2017, 139, 4042-4051. doi:10.1021/jacs.6b12124

28. Gibson, J.; Monkman, A. P.; Penfold, T. J. ChemPhysChem 2016, 17, 2956-2961. doi:10.1002/cphc.201600662

29. dos Santos, P. L.; Ward, J. S.; Bryce, M. R.; Monkman, A. P. J. Phys. Chem. Lett. 2016, 7, 3341-3346. doi:10.1021/acs.jpclett.6b01542

30. de Sa Pereira, D.; dos Santos, P. L.; Ward, J. S.; Data, P.; Okazaki, M.; Takeda, Y.; Minakata, S.; Bryce, M. R.; Monkman, A. P. Sci. Rep. 2017, 7, No. 6234. doi:10.1038/s41598-017-06568-3

31. Turkoglu, G.; Cinar, M. E.; Ozturk, T. Molecules 2017, 22, No. 1522. doi:10.3390/molecules22091522

32. Kinoshita, M.; Kita, H.; Shirota, Y. Adv. Funct. Mater. 2002, 12, 780-786. doi:10.1002/adfm.200290007

33. Nagai, A.; Kobayashi, S.; Nagata, Y.; Kokado, K.; Taka, H.; Kita, H.; Suzuri, Y.; Chujo, Y. J. Mater. Chem. 2010, 20, 5196-5201. doi:10.1039/b924729g

34. Kitamoto, Y.; Namikawa, T.; Ikemizu, D.; Miyata, Y.; Suzuki, T.; Kita, H.; Sato, T.; Oi, S. J. Mater. Chem. C 2015, 3, 9122-9130. doi:10.1039/C5TC01380A

35. Kitamoto, Y.; Namikawa, T.; Suzuki, T.; Miyata, Y.; Kita, H.; Sato, T.; Oi, S. Org. Electron. 2016, 34, 208-217. doi:10.1016/j.orgel.2016.04.030

36. Lee, Y. H.; Park, S.; Oh, J.; Shin, J. W.; Jung, J.; Yoo, S.; Lee, M. H. ACS Appl. Mater. Interfaces 2017, 9, 24035-24042. doi:10.1021/acsami.7b05615

37. Suzuki, K.; Kubo, S.; Shizu, K.; Fukushima, T.; Wakamiya, A.; Murata, Y.; Adachi, C.; Kaji, H. Angew. Chem., Int. Ed. 2015, 54, 15231-15235. doi:10.1002/anie.201508270

38. Numata, M.; Yasuda, T.; Adachi, C. Chem. Commun. 2015, 51, 9443-9446. doi:10.1039/C5CC00307E

39. Hatakeyama, T.; Shiren, K.; Nakajima, K.; Nomura, S.; Nakatsuka, S.; Kinoshita, K.; Ni, J.; Ono, Y.; Ikuta, T. Adv. Mater. 2016, 28, 2777-2781. doi:10.1002/adma.201505491

40. Zhang, Q.; Li, J.; Shizu, K.; Huang, S.; Hirata, S.; Miyazaki, H.; Adachi, C. J. Am. Chem. Soc. 2012, 134, 14706-14709. doi:10.1021/ja306538w

41. Wu, S.; Aonuma, M.; Zhang, Q.; Huang, S.; Nakagawa, T.; Kuwabara, K.; Adachi, C. J. Mater. Chem. C 2014, 2, 421-424. doi:10.1039/C3TC31936A 
42. Sun, K.; Xie, X.; Liu, Y.; Jiang, W.; Ban, X.; Huang, B.; Sun, Y. J. Mater. Chem. C 2016, 4, 8973-8979. doi:10.1039/C6TC02634F

43. Zhang, Q.; Li, B.; Huang, S.; Nomura, H.; Tanaka, H.; Adachi, C. Nat. Photonics 2014, 8, 326-332. doi:10.1038/nphoton.2014.12

44. Wu, Z.; Luo, J.; Sun, N.; Zhu, L.; Sun, H.; Yu, L.; Yang, D.; Qiao, X.; Chen, J.; Yang, C.; Ma, D. Adv. Funct. Mater. 2016, 26, 3306-3313. doi:10.1002/adfm.201505602

45. Zhang, Q.; Tsang, D.; Kuwabara, H.; Hatae, Y.; Li, B.; Takahashi, T.; Lee, S. Y.; Yasuda, T.; Adachi, C. Adv. Mater. 2015, 27, 2096-2100. doi:10.1002/adma.201405474

46. Sun, J. W.; Baek, J. Y.; Kim, K.-H.; Moon, C.-K.; Lee, J.-H.; Kwon, S.-K.; Kim, Y.-H.; Kim, J.-J. Chem. Mater. 2015, 27, 6675-6681. doi:10.1021/acs.chemmater.5b02515

47. Sun, J. W.; Baek, J. Y.; Kim, K.-H.; Huh, J.-S.; Kwon, S.-K.; Kim, Y.-H.; Kim, J.-J. J. Mater. Chem. C 2017, 5, 1027-1032. doi:10.1039/C6TC04653C

48. Hirata, S.; Sakai, Y.; Masui, K.; Tanaka, H.; Lee, S. Y.; Nomura, H.; Nakamura, N.; Yasumatsu, M.; Nakanotani, H.; Zhang, Q.; Shizu, K.; Miyazaki, H.; Adachi, C. Nat. Mater. 2015, 14, 330-336. doi:10.1038/nmat4154

49. Cui, L.-S.; Deng, Y.-L.; Tsang, D. P.-K.; Jiang, Z.-Q.; Zhang, Q.; Liao, L.-S.; Adachi, C. Adv. Mater. 2016, 28, 7620-7625. doi:10.1002/adma.201602127

50. Yang, J.; Chen, C.; Ji, H.; Ma, W.; Zhao, J. J. Phys. Chem. B 2005, 109, 21900-21907. doi:10.1021/jp0540914

51. Shizu, K.; Noda, H.; Tanaka, H.; Taneda, M.; Uejima, M.; Sato, T.; Tanaka, K.; Kaji, H.; Adachi, C. J. Phys. Chem. C 2015, 119, 26283-26289. doi:10.1021/acs.jpcc.5b07798

52. Serevičius, T.; Nakagawa, T.; Kuo, M.-C.; Cheng, S.-H.; Wong, K.-T.; Chang, C.-H.; Kwong, R. C.; Xia, S.; Adachi, C. Phys. Chem. Chem. Phys. 2013, 15, 15850-15855. doi:10.1039/c3cp52255e

53. Kim, M.; Jeon, S. K.; Hwang, S.-H.; Lee, J. Y. Adv. Mater. 2015, 27 , 2515-2520. doi:10.1002/adma.201500267

54. Cha, J.-R.; Lee, C. W.; Gong, M.-S. Dyes Pigm. 2017, 140, 399-406. doi:10.1016/j.dyepig.2017.01.053

55. Cha, J.-R.; Lee, C. W.; Lee, J. Y.; Gong, M.-S. Dyes Pigm. 2016, 134, 562-568. doi:10.1016/j.dyepig.2016.08.023

56. Cui, L.-S.; Nomura, H.; Geng, Y.; Kim, J. U.; Nakanotani, H.; Adachi, C. Angew. Chem., Int. Ed. 2017, 56, 1571-1575. doi:10.1002/anie.201609459

57. Nakao, K.; Sasabe, H.; Komatsu, R.; Hayasaka, Y.; Ohsawa, T.; Kido, J. Adv. Opt. Mater. 2017, 5, 1600843. doi:10.1002/adom.201600843

58. Ganesan, P.; Ranganathan, R.; Chi, Y.; Liu, X.-K.; Lee, C.-S.; Liu, S.-H.; Lee, G.-H.; Lin, T.-C.; Chen, Y.-T.; Chou, P.-T. Chem. - Eur. J. 2017, 23, 2858-2866. doi:10.1002/chem.201604883

59. Park, I. S.; Lee, J.; Yasuda, T. J. Mater. Chem. C 2016, 4 , 7911-7916. doi:10.1039/C6TC02027E

60. Shao, S.; Hu, J.; Wang, X.; Wang, L.; Jing, X.; Wang, F. J. Am. Chem. Soc. 2017, 139, 17739-17742. doi:10.1021/jacs.7b10257

61. Dumur, F.; Guillaneuf, Y.; Guerlin, A.; Wantz, G.; Bertin, D.; Miomandre, F.; Clavier, G.; Gigmes, D.; Mayer, C. R. Macromol. Chem. Phys. 2011, 212, 1616-1628. doi:10.1002/macp.201100167

62. Lee, S. Y.; Adachi, C.; Yasuda, T. Adv. Mater. 2016, 28, 4626-4631. doi:10.1002/adma.201506391

63. Zhang, Y.; Ni, Y.-P.; He, M.-X.; Wang, X.-L.; Chen, L.; Wang, Y.-Z. Polymer 2015, 60, 50-61. doi:10.1016/j.polymer.2015.01.030
64. Yamamura, M.; Saito, T.; Nabeshima, T. J. Am. Chem. Soc. 2014, 136, 14299-14306. doi:10.1021/ja507913u

65. Yamamura, M.; Sukegawa, K.; Nabeshima, T. Chem. Commun. 2015, 51, 12080-12083. doi:10.1039/C5CC04194E

66. Yamamura, M.; Hasegawa, T.; Nabeshima, T. Org. Lett. 2016, 18, 816-819. doi:10.1021/acs.orglett.6b00105

67. Al-Hiari, Y. M.; Sweileh, B. A. Asian J. Chem. 2006, 18, 2285-2298.

68. Yu, W.; Coburn, C. A.; Yang, D.-Y.; Meinke, P. T.; Wong, M.; Rosenblum, S. B.; Chen, K. X.; Njoroge, G. F.; Chen, L.; Dwyer, M. P.; Jiang, Y.; Nair, A. G.; Selyutin, O.; Tong, L.; Zeng, Q.; Zhong, B.; Ji, T.; Hu, B.; Agrawal, S.; Xia, E.; Zhai, Y.; Liu, R.; Kong, R.; Ingravallo, P.; Asante-Appiah, E.; Nomeir, A.; Fells, J.; Kozlowski, J. A. Bioorg. Med. Chem. Lett. 2016, 26, 3158-3162. doi:10.1016/j.bmcl.2016.04.084

69. Liu, W.; Zheng, C.-J.; Wang, K.; Chen, Z.; Chen, D.-Y.; Li, F.; Ou, X.-M.; Dong, Y.-P.; Zhang, X.-H. ACS Appl. Mater. Interfaces 2015, 7, 18930-18936. doi:10.1021/acsami.5b05648

70. Li, N.; Wang, P.; Lai, S.-L.; Liu, W.; Lee, C.-S.; Lee, S.-T.; Liu, Z. Adv. Mater. 2010, 22, 527-530. doi:10.1002/adma.200902430

71. You, J.; Lai, S.-L.; Liu, W.; Ng, T.-W.; Wang, P.; Lee, C.-S. J. Mater. Chem. 2012, 22, 8922-8929. doi:10.1039/c2jm00078d

72. Pan, K.-C.; Li, S.-W.; Ho, Y.-Y.; Shiu, Y.-J.; Tsai, W.-L.; Jiao, M.; Lee, W.-K.; Wu, C.-C.; Chung, C.-L.; Chatterjee, T.; Li, Y.-S.; Wong, K.-T.; Hu, H.-C.; Chen, C.-C.; Lee, M.-T. Adv. Funct. Mater. 2016, 26, 7560-7571. doi:10.1002/adfm.201602501

73. Sasabe, H.; Onuma, N.; Nagai, Y.; Ito, T.; Kido, J. Chem. - Asian J. 2017, 12, 648-654. doi:10.1002/asia.201601641

74. Duan, C.; Li, J.; Han, C.; Ding, D.; Yang, H.; Wei, Y.; Xu, H. Chem. Mater. 2016, 28, 5667-5679. doi:10.1021/acs.chemmater.6b01691

75. Mallesham, G.; Swetha, C.; Niveditha, S.; Mohanty, M. E.; Babu, N. J.; Kumar, A.; Bhanuprakash, K.; Rao, V. J. J. Mater. Chem. C 2015, 3, 1208-1224. doi:10.1039/C4TC01753F

76. Zhang, D.; Cai, M.; Bin, Z.; Zhang, Y.; Zhang, D.; Duan, L. Chem. Sci. 2016, 7, 3355-3363. doi:10.1039/C5SC04755B

77. Tanimoto, S.; Suzuki, T.; Nakanotani, H.; Adachi, C. Chem. Lett. 2016, 45, 770-772. doi:10.1246/cl.160290

78. Kim, G. H.; Lampande, R.; Im, J. B.; Lee, J. M.; Lee, J. Y.; Kwon, J. H. Mater. Horiz. 2017, 4, 619-624. doi:10.1039/C6MH00579A

79. Sasabe, H.; Toyota, N.; Nakanishi, H.; Ishizaka, T.; Pu, Y.-J.; Kido, J. Adv. Mater. 2012, 24, 3212-3217. doi:10.1002/adma.201200848

80. Cui, L.-S; Liu, Y.; Yuan, X.-D.; Li, Q.; Jiang, Z.-Q.; Liao, L.-S. J. Mater. Chem. C 2013, 1, 8177-8185. doi:10.1039/c3tc31675k

81. Mazetyte, D.; Krucaite, G.; Grazulevicius, J. V.; Chiang, C. I.; Yang, F. C.; Jou, J. H.; Grigalevicius, S. Opt. Mater. 2013, 35, 604-608. doi:10.1016/j.optmat.2012.10.054

82. Byeon, S. Y.; Jeon, S. K.; Hwang, S.-H.; Lee, J. Y. Dyes Pigm. 2015, 120, 258-264. doi:10.1016/j.dyepig.2015.04.024

83. Noda, H.; Kabe, R.; Adachi, C. Chem. Lett. 2016, 45, 1463-1466. doi:10.1246/cl.160814

84. Rajamalli, P.; Senthilkumar, N.; Gandeepan, P.; Huang, P.-Y.; Huang, M.-J.; Ren-Wu, C.-Z.; Yang, C.-Y.; Chiu, M.-J.; Chu, L.-K.; Lin, H.-W.; Cheng, C.-H. J. Am. Chem. Soc. 2016, 138, 628-634. doi:10.1021/jacs.5b10950

85. Shih, C.-H.; Rajamalli, P.; Wu, C.-A.; Chiu, M.-J.; Chu, L.-K.; Cheng, C.-H. J. Mater. Chem. C 2015, 3, 1491-1496. doi:10.1039/C4TC02348J

86. Chou, H.-H.; Cheng, C.-H. Adv. Mater. 2010, 22, 2468-2471. doi:10.1002/adma.201000061 
87. Rajamalli, P.; Senthilkumar, N.; Gandeepan, P.; Ren-Wu, C.-C.; Lin, H.-W.; Cheng, C.-H. ACS Appl. Mater. Interfaces 2016, 8 , 27026-27034. doi:10.1021/acsami.6b10678

88. Rajamalli, P.; Senthilkumar, N.; Gandeepan, P.; Ren-Wu, C.-Z.; Lin, H.-W.; Cheng, C.-H. J. Mater. Chem. C 2016, 4, 900-904. doi:10.1039/C5TC03943F

89. Rajamalli, P.; Thangaraji, V.; Senthilkumar, N.; Ren-Wu, C.-C.; Lin, H.-W.; Cheng, C.-H. J. Mater. Chem. C 2017, 5, 2919-2926. doi:10.1039/C7TC00457E

90. Rajamalli, P.; Senthilkumar, S.; Huang, P.-Y.; Ren-Wu, C.-C.; Lin, H.-W.; Cheng, C.-H. J. Am. Chem. Soc. 2017, 139, 10948-10951. doi:10.1021/jacs.7b03848

91. Adachi, C.; Tsutsui, T.; Saito, S. Appl. Phys. Lett. 1989, 55, 1489-1491. doi:10.1063/1.101586

92. Kido, J.; Ohtaki, C.; Hongawa, K.; Okuyama, K.; Nagai, K. Jpn. J. Appl. Phys. 1993, 32, L917-L920. doi:10.1143/JJAP.32.L917

93. Kulkarni, A. P.; Tonzola, C. J.; Babel, A.; Jenekhe, S. A. Chem. Mater. 2004, 16, 4556-4573. doi:10.1021/cm049473।

94. Lee, J.; Shizu, K.; Tanaka, H.; Nomura, H.; Yasuda, T.; Adachi, C. J. Mater. Chem. C 2013, 1, 4599-4604. doi:10.1039/c3tc30699b

95. Valchanov, G.; Ivanova, A.; Tadjer, A.; Chercka, D.; Baumgarten, M. J. Phys. Chem. A 2016, 120, 6944-6955. doi:10.1021/acs.jpca.6b06680

96. Dumur, F.; Goubard, F. New J. Chem. 2014, 38, 2204-2224. doi:10.1039/c3nj01537h

97. Li, Y.; Li, X.-L.; Chen, D.; Cai, X.; Xie, G.; He, Z.; Wu, Y.-C.; Lien, A.; Cao, Y.; Su, S.-J. Adv. Funct. Mater. 2016, 26, 6904-6912. doi:10.1002/adfm.201602507

98. Sohn, S.; Koh, B. H.; Baek, J. Y.; Byun, H. C.; Lee, J. H.; Shin, D.-S.; Ahn, H.; Lee, H.-K.; Hwang, J.; Jung, S.; Kim, Y.-H. Dyes Pigm. 2017, 140, 14-21. doi:10.1016/j.dyepig.2017.01.010

99. Mayr, C.; Lee, S. Y.; Schmidt, T. D.; Yasuda, T.; Adachi, C.; Brütting, W. Adv. Funct. Mater. 2014, 24, 5232-5239. doi:10.1002/adfm.201400495

100.Mayr, C.; Schmidt, T. D.; Brütting, W. Appl. Phys. Lett. 2014, 105, 183304. doi:10.1063/1.4901341

101.Kim, K.-H.; Liao, J.-L.; Lee, S. W.; Sim, B.; Moon, C.-K.; Lee, G.-H.; Kim, H. J.; Chi, Y.; Kim, J.-J. Adv. Mater. 2016, 28, 2526-2532. doi:10.1002/adma.201504451

\section{License and Terms}

This is an Open Access article under the terms of the Creative Commons Attribution License (http://creativecommons.org/licenses/by/4.0), which permits unrestricted use, distribution, and reproduction in any medium, provided the original work is properly cited.

The license is subject to the Beilstein Journal of Organic Chemistry terms and conditions: (https://www.beilstein-journals.org/bjoc)

The definitive version of this article is the electronic one which can be found at: doi:10.3762/bjoc. 14.18 